Trabajos y Comunicaciones, 2da. Época, No 47, e051, enero-junio 2018. ISSN 2346-8971

Universidad Nacional de La Plata.

Facultad de Humanidades y Ciencias de la Educación.

Departamento de Historia

\title{
Desde los primeros puestos rurales hasta la estancia moderna del sur bonaerense: un recorrido arqueologico
}

\author{
From the first rural puestos to the moderm farm of the south of \\ Buenos Aires province: an archaeological trail
}

\author{
Vanesa Natalia Bagaloni * \\ * Universidad Maimónides - CONICET, CEBBAD, Departamento de Ciencias Naturales y \\ Antropológicas, Fundación de Historia Natural Félix de Azara, Argentina | \\ bagaloni.vanesa@maimonides.edu
}

PALABRAS CLAVE

Puesto rural

Estancia moderna

Segunda mitad del siglo XIX

Sur bonaerense

Arqueología histórica

\section{KEYWORDS}

Rural puestos

Modern farm

Second half of the 19th century

Southern Buenos Aires

Historical archaeology

\section{RESUMEN}

El avance de la población criolla sobre territorio indígena en el sur bonaerense desde la segunda mitad del siglo XIX implicó la emergencia, conformación y consolidación de un nuevo ámbito, el rural. En este trabajo, se discuten a nivel regional y comparativo los resultados del estudio arqueológico de los puestos rurales Las Toscas 3 y Máximo Ortiz y la estancia La Libertad. Dicha discusión se centró en el uso del espacio en las instalaciones rurales referidas, la producción y explotación de animales domésticos, la dieta rural, los hábitos de consumo relacionados con una gran cantidad de artículos y bienes europeos, entre otros aspectos.

\section{ABSTRACT}

The advance of the creole population over indigenous territory in the south of Buenos Aires province since the second half of the 19th century implied the emergence, conformation and consolidation of a new field, the rural. In this paper, the results of the archaeological study of the rural posts Las Toscas 3 and Máximo Ortiz and the farm La Libertad are discussed at a regional and comparative level. This discussion focused on the use of space in such rural facilities, the production and exploitation of domestic animals, the rural diet, consumption habits related to a large number of European goods and goods, among other aspects. 


\section{Introducción}

Por medio del sistema de enfiteusis y posteriormente, de arrendamientos y subarrendamientos, la población no indígena comenzó a ocupar las tierras del sur bonaerense entre 1830 y 1850, sustraídas a los pueblos originarios (Bagaloni, 2014a; Eiras \& Vassolo, 1981; Infesta, 2003). Luego del avance militar, constituido a partir de la instalación de fuertes y fortines en la frontera Sur y Costa Sur, los terrenos fueron comprados en las décadas de 1860 y 1870 (Eiras \& Vassolo, 1981; Valencia, 2005). Estos primeros asentamientos criollos fronterizos no militares constituyeron unidades productivas permanentes, fundamentalmente ganaderas, que no fueron ajenas a las modificaciones socioeconómicas y culturales que se gestaron hacia mediados de siglo XIX. Es así que, en la segunda mitad de la centuria, en estos asentamientos nacieron nuevas maneras de concebir el espacio al interior de las viviendas, se produjo el compartimento de los campos y el paso de la actividad ganadera extensiva a una intensiva y cada vez más especializada. Todo se complejizó y se centralizó. Dentro de las estancias, además del casco principal, se encontraban puestos de distinta jerarquías y chacras a cargo del dueño principal, mayordomos, capataces, chacareros, puesteros y peones, respectivamente (Reguera, 1999). En este marco, los pobladores rurales del sur bonaerense adquirieron nuevos hábitos domésticos y prácticas sociales así como necesidades económicas (Brittez, 2000; Carrera, 2014; Correa \& Wibaux, 2000; Mayo, 2000).

De esta manera, el mundo rural pampeano se modificó, estableciéndose nuevos paisajes y hábitos que pudieron ser conocidos arqueológicamente. Desde la arqueología histórica se ha avanzado en el abordaje de este nuevo mundo rural emergente. La arqueología histórica rural estudia en sentido amplio todas las instalaciones criollas total -p.e. estancias, chacras y puestos- y/o parcialmente -p.e. asentamientos militares, tolderías indígenas, casas de negocios y pulperías- productivas y emplazadas en el espacio fronterizo y/o rural pampeano (Bagaloni, 2014a, 2014b). Estos asentamientos constituyeron parte de una red que componía un sistema que los conectaba y los mantenía; un ámbito integrado por diversas personas, múltiples situaciones, relaciones y contextos. Desde esta perspectiva, nuestras interpretaciones se basaron en el análisis y discusión crítica tanto de los restos arqueológicos como de los documentos escritos y las fuentes gráficas.

A continuación desarrollaremos este recorrido de transformaciones espaciales, económicas y sociales a través de los sitios arqueológicos estudiados por la autora: los puestos Las Toscas 3 (LT3) y Máximo Ortiz (MO) y, la estancia La Libertad (LL); y en comparación con otros sitios arqueológicos productivos contemporáneos bonaerenses (Figura 1). La microrregión de estudio abarca los partidos de San Cayetano, Tres Arroyos, Gonzales Chaves y sur de Benito Juárez. El objetivo del artículo estuvo orientado a conocer, analizar y discutir distintos aspectos relacionados con el uso del espacio en los puestos rurales y estancias, la producción y explotación de animales domésticos, la dieta rural, los hábitos de consumo de una gran cantidad de artículos y bienes europeos por parte de las poblaciones rurales bonaerenses, entre otros; desde la comparación de casos arqueológicos y la integración de las microhistorias (Levi, 1993) de algunos de los habitantes de dichos asentamientos, sobre todo de Teófilo C. Gomila. 


\section{Figura 1}

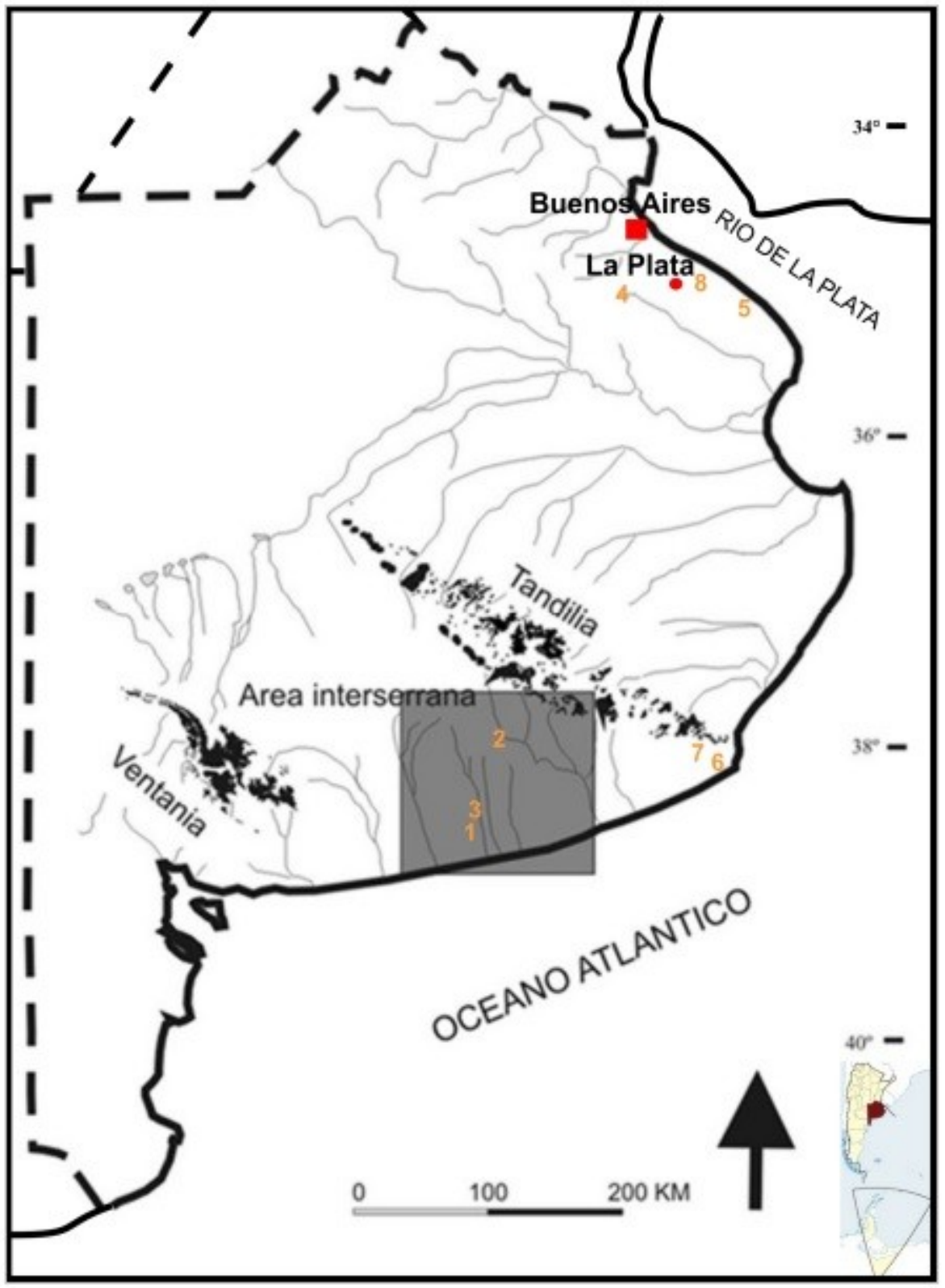

Mapa de la provincia de Buenos Aires con la microrregión de estudio de la autora (sombreado gris) y la ubicación de los sitios arqueológicos tratados en este artículo: 1. LT3, 2. MO, 3. LL, 4. V2, 5. ESI, 6. EIn, 7. EBV y 8. EIr.

Partimos de una serie de conjeturas principales y de base que se sucedieron en los ámbitos rurales de la región en la segunda mitad del siglo XIX: 1) la complejización, sectorización y jerarquización del espacio doméstico y rural; 2) la especialización e intensificación productiva basada en la cría de ganado, fundamentalmente ovino y vacuno, y en la agricultura de forrajes y de subsistencia; 3) la ampliación de las prácticas sociales y la categorización de las relaciones laborales; y 4) el consumo de una variada gama de artículos y bienes con un claro predominio de productos de procedencia extranjera que se incorporaron a la vida cotidiana producto de la modernización del mundo rural. El abordaje arqueológico de tales presunciones exclusivamente en sitios rurales de carácter civil y 
agropecuario -como lo constituyen los puestos y estancias aquí abordadas- constituye un primer acercamiento sobre diversas características, transformaciones y problemas propios de este tipo de asentamientos, que no se han tratado de manera integral ni distintiva, por lo menos, en el campo de la arqueología. Hasta el momento, sólo contamos con los estudios de F. Brittez (2000, 2009) quien aborda algunas de estas temáticas en un conjunto de casos arqueológicos de distinta índole, entre los que se encuentran las estancias y puestos rurales.

\section{Los sitios arqueológicos estudiados}

Las investigaciones desarrolladas en estos tres sitios ya han sido publicadas previamente (Bagaloni, 2010, 2014b; Bagaloni, Perdomo \& Ainchil, 2011; Bagaloni \& Carrascosa Estenoz, 2013; Bagaloni \& Martí, 2013) por lo que aquí se sintetizan los resultados del análisis de los conjuntos arqueológicos hallados (Tabla 1). El estudio de los puestos rurales estuvo guiado por un conjunto de interrogantes tales como cuáles eran las características relevantes de la materialidad de estos primeros asentamientos rurales, cuál era la forma de subsistencia de sus habitantes, qué hábitos domésticos mantenían, con qué tecnologías contaban, qué tipo de prácticas de producción, consumo y descarte tenían, qué artículos locales y europeos utilizaban y/o consumían y cómo los obtenían, cómo era el uso del espacio, cómo se conformó y consolidó un nuevo paisaje rural mientras y luego de las ocupaciones indígenas y, qué transformaciones experimentaron desde mediados hasta fines del siglo XIX. Los dos sitios arqueológicos, uno superficial (LT3) y otro en estratigrafía (MO), atribuidos a poblaciones y/o puestos rurales precursores en la microrregión de estudio ocuparon los terrenos, por lo menos, desde la década de 1860 y al exterior de la línea oficial de frontera según lo registrado en distintas fuentes documentales (Bagaloni, 2010, 2014a, 2014b).

El sitio LT3 se encontró al este del partido de Tres Arroyos y al noroeste de la laguna Las Toscas y forma parte de la localidad homónima (Bagaloni, 2010, 2014a, 2014b). Los materiales arqueológicos se registraron en superficie distribuidos en un área acotada de la playa. El conjunto arqueológico $(n=8350)$ se compone mayormente de restos vítreos y óseos seguidos por artefactos líticos, ladrillos, metales y materiales cerámicos. Este sitio presentó un origen múltiple y constituye un palimpsesto formado por una concentración de materiales indígenas y criollos producto de distintas ocupaciones: 1) una indígena de momentos prehispánicos dada por la presencia de artefactos líticos, 2) otra criolla de momentos posthispánicos de la segunda mitad del siglo XIX sustentada por los restos vítreos y cerámicos y 3) ocupaciones recientes dada por algunos de los elementos óseos y metálicos posiblemente dejados por los posteriores habitantes y pescadores de la laguna.

Tabla 1. Síntesis de los conjuntos arqueológicos estudiados por la autora.

\begin{tabular}{|l|l|l|l|}
\hline $\begin{array}{l}\text { Sitio/ } \\
\text { Material }\end{array}$ & $\begin{array}{l}\text { Las Toscas 3 } \\
\text { (Pdo. Tres Arroyos) }\end{array}$ & $\begin{array}{l}\text { Máximo Ortiz } \\
\text { (Pdo. San Cayetano) }\end{array}$ & $\begin{array}{l}\text { La Libertad } \\
\text { (Pdo. San Cayetano) }\end{array}$ \\
\hline Vidrio & $\begin{array}{l}\text { Botellas cuadradas de } \\
\text { ginebra (limetas) yotellas cuadradas }\end{array}$ & $\begin{array}{l}\text { Vidrio plano. Botellas } \\
\text { cilíndricas de vino, } \\
\text { cilíndricas de ginebra. Vaso. } \\
\text { cerveza, vino, } \\
\text { hesperidina. Frascos de }\end{array}$ & $\begin{array}{l}\text { champagne, } \\
\text { cuadradas de ginebra, } \\
\text { hesascos de perfumería }\end{array}$ \\
\hline
\end{tabular}




\begin{tabular}{|c|c|c|c|}
\hline & $\begin{array}{l}\text { perfumería y/o farmacia. } \\
\text { Vaso. }\end{array}$ & & $\begin{array}{l}\text { y farmacia. Vasos. } \\
\text { Botones. }\end{array}$ \\
\hline Óseo & $\begin{array}{l}\text { Fauna doméstica (caballo, } \\
\text { vaca y oveja) y silvestre } \\
\text { autóctona } \\
\text { armadillos, vizcacha) e } \\
\text { introducida } \\
\text { europea). Aves y peces. }\end{array}$ & $\begin{array}{l}\text { Mamíferos pequeños } \\
\text { y medianos, } \\
\text { armadillos (peludo, } \\
\text { mulita), roedores y } \\
\text { aves. }\end{array}$ & $\begin{array}{lr}\begin{array}{l}\text { Fauna } \\
\text { (oveja, vaca, }\end{array} & \begin{array}{r}\text { doméstica } \\
\text { cerdo) y }\end{array} \\
\text { autóctona } \\
\text { comadreja) } \\
\text { introducida } \\
\text { (peludo, } \\
\text { europea). } \\
\text { cérvidos, cánidos. Aves } \\
\text { (liebre } \\
\text { Rasseriforme, gallina, } \\
\text { ñandú). }\end{array}$ \\
\hline Constructivo & $\begin{array}{l}\text { Ladrillos de fabricación } \\
\text { manual }\end{array}$ & - & $\begin{array}{l}\text { Ladrillos artesanales. } \\
\text { Baldosas nacionales e } \\
\text { importadas. Azulejos, } \\
\text { tejas, revestimientos de } \\
\text { paredes y pisos. }\end{array}$ \\
\hline Metal & $\begin{array}{l}\text { Clavos (uno con cabeza y } \\
\text { sección } \\
\text { alambres, redonda), } \\
\text { elementos de pesca }\end{array}$ & $\begin{array}{l}\text { Clavo de cabeza y } \\
\text { sección redonda }\end{array}$ & $\begin{array}{lr}\text { Alambre, calvos de } \\
\text { sección cuadrada y } \\
\text { redonda, } \\
\text { perillas, cerrojos, } \\
\begin{array}{l}\text { argollas, bulón, chapa, } \\
\text { hebillas, } \\
\text { cuchillo, proyectiles y } \\
\text { vainas. }\end{array}\end{array}$ \\
\hline Cerámica & $\begin{array}{l}\text { Loza whiteware lisa y } \\
\text { decorada (platos, tazas, } \\
\text { bowls y bacín), botella de } \\
\text { gres de ginebra, cazuela de } \\
\text { porcelana de pipa. }\end{array}$ & $\begin{array}{l}\text { Loza pearlware } \\
\text { decorada (plato) }\end{array}$ & $\begin{array}{l}\text { Lozas pearlware y } \\
\text { whiteware lisas y } \\
\text { decorada (platos, tazas, } \\
\text { fuente y jarro). Botella } \\
\text { de gres de ginebra y/o } \\
\text { agua mineral y de } \\
\text { cerveza. Tintero de } \\
\text { gres. Pipas de caolín. } \\
\text { Taza y figurilla de } \\
\text { porcelana. Cerámica } \\
\text { roja-negra. Cerámica } \\
\text { indígena. Botón. }\end{array}$ \\
\hline Cronología & Último tercio del siglo XIX & $\begin{array}{l}\text { Último tercio del } \\
\text { siglo XIX }\end{array}$ & $\begin{array}{l}\text { Último tercio del XIX } \\
\text {-principios de siglo } \\
\text { XX }\end{array}$ \\
\hline
\end{tabular}

En relación a la segunda ocupación, en el duplicado de mensura de Tres Arroyos No 64 (1875), en el sector norte de esta laguna, se observa un asentamiento denominado “puesto Chorroarin”, el cual pudo haber sido un puesto netamente ganadero. Teniendo en cuenta la evolución de la tierra pública, esta área se encontraba habitada por poblaciones criollas, supuestamente, desde 1838 (según duplicado de mensura de Tres Arroyos $N^{\circ}$ 51, 1871). Este terreno donde se ubicaba el puesto estaba arrendado desde principios de 1860 por Carlos M. Baigorri, quien a fines de esta década entra en conflicto con su subarrendatario estimando que desde 1865 hasta principios de 1869 la "ocupación indebida de mi campo de las Toscas (...) ha sostenido hasta hoy 2000 cabezas de ganado vacuno, 
500 mil lanares y 150 caballares” (Legajo 115, Expediente N 9154/0, 1868, Escribanía Mayor de Gobierno, Archivo Histórico de la Provincia de Buenos Aires).

Por otro lado, el sitio MO se localizó en el partido de San Cayetano, en la margen derecha del arroyo Pescado Castigado, en una lomada. En dicha lomada se realizaron dos sondeos y una recolección superficial, hallándose una diversidad de materiales arqueológicos $(n=281)$. Estos corresponden mayormente a restos faunísticos y vítreos, seguidos por cerámicos y metales. En cuanto a la documentación escrita en este sector se registró el puesto Máximo Ortiz habitado desde 1855 (duplicado de mensura $\mathrm{N}^{\circ} 50$ del partido de Gonzales Chaves correspondiente a la testamentaria de Don Juan Rosa Ortiz, 1880).

A pesar de las características diferentes de ambos sitios es posible compararlos arqueológicamente. El objetivo de este cotejo es reconocer tendencias generales y explorar las similitudes y diferencias sobre las viviendas rurales, funcionalidades, hábitos y modos de vida en el espacio rural del sur bonaerense. En ambos sitios, el número y la diversidad de los materiales vítreos y óseos ha sido mayor en relación con los restos cerámicos, de metal y los elementos constructivos. Dentro del conjunto vítreo de ambos sitios, se consignaron limetas y vasos. En LT3, también se hallaron botellas cilíndricas y frascos. En el conjunto faunístico de los dos sitios se encontraron mamíferos de distinto porte, armadillos y aves. Además, en LT3 se registraron restos de fauna silvestre como vizcacha, coipo, liebre europea así como un pez. En ambos sitios se identificaron huellas de corte sobre todo en mamíferos. En MO, dos costillas de mamífero mediano -probable oveja- con un alto grado de meteorización presentaron huellas de descarne así como una porción de diáfisis de hueso largo de mamífero pequeño. Asimismo, se dio el aprovechamiento de dasipódidos. En LT3 únicamente se han identificado marcas de procesamiento en ungulados domésticos -oveja, vaca y posiblemente caballo-. Estas huellas se atribuyeron a actividades de cuereo, desarticulación y/o fileteo. Además del registro arqueofaunístico, las fuentes escritas como la antes citada para LT3 apoyarían la idea de la cría y explotación de ganado vacuno, ovino y caballar de manera extensiva, por lo menos, hasta la década de 1860.

Ha sido importante en estos sitios el hallazgo de materiales cerámicos -loza, gres, porcelana- ya que nos permiten conocer los hábitos personales y estilos de mesa, así como realizar estimaciones cronológicas en conjunto con el material vítreo. El estudio de las botellas de ginebra holandesa, de vino francés e inglés, de sidra o champagne, de Hesperidina, los frascos, la vajilla de loza inglesa y la pipa de porcelana europea ubica a estos contextos arqueológicos hacia la segunda mitad del siglo XIX. Tanto el registro vítreo como el cerámico reflejan distintas prácticas domésticas y sociales, tales como el consumo de bebidas alcohólicas y el uso de una específica vajilla de mesa específica acorde a las modas que entonces estaban imponiéndose (Carrera, 2004; Correa \& Wibaux, 2000; Mayo, 2000). Y vemos también, que para el caso de LT3, se encuentran representados hábitos relacionados con la higiene y el cuidado personal. Además en este sitio los fragmentos de ladrillos y los metales podrían corresponderse con parte de la incipiente infraestructura de los puestos rurales. Por último, queremos destacar la importancia del abordaje arqueológico de este tipo de instalaciones. Primero, los puestos rurales han sido los asentamientos más difíciles de ubicar durante las prospecciones arqueológicas aunque fueron los que estaban mayormente representados en los duplicados de mensura estudiados (Bagaloni 2014a, 2014b). Segundo, hasta el momento no 
existen otros estudios arqueológicos sobre puestos rurales de carácter agro-ganadero en el sur bonaerense. Tercero, estas iniciales viviendas rurales han sido primordiales en la conformación de los primeros poblados y pueblos de la microrregión.

Por orto lado, la investigación sobre las estancias procuró comprender la modalidad de expansión territorial de estos establecimientos vinculados a distintas actividades agropecuarias así como los circuitos de abastecimiento, producción y consumo de bienes necesarios para la vida fronteriza y/o rural en el sur bonaerense, los hábitos cotidianos, los patrones alimenticios, la intensa y compleja red de relaciones sociales, entre otros. Estos aspectos se fueron configurando durante el proceso, no sólo de conformación de los pueblos, sino también de consolidación del país basado en ideales liberales y progresistas, sumergido en un contexto de mundo moderno, industrial y capitalista (Garavaglia \& Gelman, 2003; Hobsbawm, 1998; Zeberio, 1999).

El sitio LL se ubicó sobre la margen derecha del arroyo Cristiano Muerto, en el partido de San Cayetano (Bagaloni, 2010, 2014a, 2014b). El conjunto arqueológico recuperado ( $n=5602$ ) tanto en superficie como en estratigrafía se compone de restos óseos seguidos de metales, vidrios, materiales constructivos y cerámicos. La muestra arqueofaunística presentó una gran diversidad taxonómica. Sin embargo, más de la mitad se atribuyó a oveja y mamíferos medianos. Asimismo, se registraron evidencias de termoalteración y modificaciones antrópicas, dadas por el uso de cuchillo, hacha y sierra manual y eléctrica, que nos indicaron distintas actividades desde el procesamiento inicial hasta el consumo de distintas especies como oveja, vaca, chancho y peludo, entre otras (Bagaloni \& Carrascosa Estenoz 2013). Dentro de los metales se distinguen diversos elementos en relación con la construcción y el mobiliario de la estancia. A partir de los conjuntos vítreos y cerámicos se reconocieron las prácticas domésticas y hábitos de mesa así como los circuitos de obtención y consumo de una variada gama de productos de origen principalmente europeo (Bagaloni 2010). En este sitio encontramos mayor diversidad que en los puestos rurales. Entre ellos, botellas de vino francés, Hesperidina, Bitter, ginebra holandesa, cerveza, frascos de perfumería y farmacia, vasos, vajilla de loza inglesa, cerámicas rojas y locales. También, se registraron elementos de uso personal que denotan la alfabetización de sus habitantes y el hábito de fumar tabaco -tintero de gres y pipas de caolín francesas-, de vestimenta -botones de cerámica y de nácar y, hebillas de metal- y constructivos locales, como por ejemplo, ladrillos de manufactura manual, baldosas y teja. Un tramo de pared derribada del casco principal fue localizado en una de las cuadrículas excavadas así como un piso de ladrillos. Por tanto, se asignó este sitio a un establecimiento tipo estancia que funcionó, por lo menos, desde 1870 hasta 1930 según lo indican los materiales arqueológicos -vítreo, cerámico y constructivo-, los duplicados de mensuras, la historiografía local y regional, el registro fotográfico, los documentos y expedientes consultados así como los relatos orales (Bagaloni, 2010, 2014a; Bagaloni \& Martí 2013). De igual forma, un rico corpus de fuentes escritas y gráficas -entre ellos, cartas, testamento, memorias y fotografías tomadas por Teófilo C. Gomila, uno de sus propietarios desde 1878- la describen como una residencia central, con un mirador y cañón, una casa de ramos generales, una vivienda para peones, otras dependencias y distintos puestos rurales como, por ejemplo, Las Martinetas y Puesto Colorado (Bagaloni 2014a). 


\section{Los casos arqueológicos comparados}

Para el sur bonaerense no contamos con antecedentes de investigaciones arqueológicas que hayan abordado de forma sistemática el análisis de las primeras viviendas rurales. Sin embargo, encontramos el estudio de dos sitios arqueológicos (Tabla 2) que fueron interpretados como casas o puestos rurales en la provincia de Buenos Aires, Vizcacheras 2 (V2) y El Santuario I (ESI). El primero de ellos, V2 constituyó un puesto de estancia donde se recuperó una gran variedad de artículos importados -vajilla, bebidas, medicamentos-, restos de fauna doméstica y silvestre con signos de procesamiento, objetos de uso personal -pipas, arma, vestimenta- y elementos constructivos que indicaban una infraestructura relativamente importante -ladrillos, tejas, baldosas, vidrios planos, clavos- (Brittez, 2000, 2002, 2004, 2009). Asimismo, el sitio ESI se trata de un contexto de consumo y descarte de alimentos y bebidas por parte de trabajadores rurales de un establecimiento productivo tipo estancia cercano al Río de la Plata (García, 2014). En cuanto a las estancias se registraron dos sitios arqueológicos en el sur y otro en el este bonaerense que presentan similar cronología que LL. El primer sitio, Estancia Infierno (EIn), ubicado en la margen derecha del arroyo Las Brusquitas, se trata de un asentamiento tipo estancia del último cuarto del siglo XIX. Entre los materiales recuperados en estratigrafía se encuentran restos óseos de Ovis aries casi en su totalidad, vajilla de loza inglesa, botellas de vidrio y gres, frascos, vasos, vidrio plano tipo ventana y pipas de caolín. Asimismo, diversos elementos metálicos y constructivos, entre éstos últimos, ladrillos y tejas marca Sacoman, azulejos Pas-de-Calais y baldosas francesas Leon Duplessy de Havre (Brittez, 2000, 2009).

Tabla 2. Conjuntos arqueológicos rurales bonaerenses

\begin{tabular}{|c|c|c|c|c|c|}
\hline $\begin{array}{l}\text { Sitio/ } \\
\text { Material }\end{array}$ & $\begin{array}{l}\text { Vizcacheras } \\
\text { Brandsen) }\end{array}$ & $\begin{array}{l}\text { El Santuario } \\
\text { I } \quad \text { (Pdo. } \\
\text { Magdalena) }\end{array}$ & $\begin{array}{l}\text { Ea. } \\
\text { Infierno } \\
\text { (Pdo. Gral. } \\
\text { Alvarado) }\end{array}$ & $\begin{array}{l}\text { Ea. } \\
\text { Ballenera } \\
\text { Vieja (Pdo. } \\
\text { Gral. } \\
\text { Alvarado) }\end{array}$ & $\begin{array}{lr}\text { Ea. } & \text { Iraola } \\
\text { (Pdo. } & \text { La } \\
\text { Plata) } & \end{array}$ \\
\hline Vidrio & $\begin{array}{l}\text { Botellas de vino, } \\
\text { Hesperidina, frascos } \\
\text { de perfumería- } \\
\text { farmacia, vaso, farol, } \\
\text { tintero, plano de } \\
\text { ventana, botones. }\end{array}$ & $\begin{array}{lr}\begin{array}{lr}\text { Botellas } \\
\text { cilíndricas }\end{array} \\
\text { vino } \\
\text { cuadradas } \\
\text { ginebra } \\
\text { holandesa, } \\
\text { botones. }\end{array}$ & $\begin{array}{l}\text { Botellas } \\
\text { cuadradas } \\
\text { de ginebra, } \\
\text { frascos, } \\
\text { vasos y } \\
\text { plano tipo } \\
\text { ventana. }\end{array}$ & $\begin{array}{l}\text { Botellas } \\
\text { frascos, } \\
\text { plano tipo } \\
\text { ventana. } \\
\text { Botones. }\end{array}$ & $\begin{array}{l}\text { Botellas } \\
\text { cuadradas de } \\
\text { ginebra, } \\
\text { cilíndricas de } \\
\text { vino y licor o } \\
\text { jerez, } \\
\text { damajuana, } \\
\text { frascos, } \\
\text { rectangular } \\
\text { de tónico, } \\
\text { plano tipo } \\
\text { ventana. }\end{array}$ \\
\hline Óseo & $\begin{array}{l}\text { Fauna } \\
\text { (oveja, vaca, caballo, } \\
\text { perro, gato, gallina, } \\
\text { pavo) y silvestre } \\
\text { (coipo, } \\
\text { perdiz, rata, aves, }\end{array}$ & $\begin{array}{l}\text { Fauna } \\
\text { doméstica } \\
\text { (oveja y vaca) } \\
\text { y silvestre } \\
\text { (venado, } \\
\text { coipo, tuco- }\end{array}$ & $\begin{array}{l}\text { Fauna } \\
\text { doméstica } \\
\text { (oveja, } \\
\text { vaca, } \\
\text { caballo, } \\
\text { gato). }\end{array}$ & $\begin{array}{l}\text { Fauna } \\
\text { doméstica } \\
\text { (vaca, } \\
\text { oveja,) y } \\
\text { silvestre } \\
\text { (armadillos, }\end{array}$ & $\begin{array}{l}\text { Fauna } \\
\text { doméstica: } \\
\text { oveja } \\
\text {-cordero-, } \\
\text { caballo con } \\
\text { marcas en }\end{array}$ \\
\hline
\end{tabular}




\begin{tabular}{|c|c|c|c|c|c|}
\hline & $\begin{array}{l}\text { peces y liebre } \\
\text { europea). }\end{array}$ & $\begin{array}{l}\text { tuco, ñandú y } \\
\text { otras r aves, } \\
\text { peces) }\end{array}$ & & $\begin{array}{l}\text { roedores } \\
\text { aves). }\end{array}$ & $\begin{array}{l}\text { lápscápulas, } \\
\text { vacas, entre } \\
\text { otros (Bogan } \\
\text { com. pers. } \\
2017)\end{array}$ \\
\hline Constructivo & $\begin{array}{l}\text { Ladrillos, baldosas y } \\
\text { tejas. }\end{array}$ & - & $\begin{array}{l}\text { Ladrillos, } \\
\text { tejas, } \\
\text { azulejos y } \\
\text { baldosas }\end{array}$ & $\begin{array}{l}\text { Ladrillos } \\
\text { baldosas. }\end{array}$ & - \\
\hline Metal & $\begin{array}{l}\text { Clavos cilíndricos de } \\
\text { cabeza redonda } \\
\text { fabricados } \\
\text { máquina, proyectiles } \\
\text { de armas de fuego, } \\
\text { hebilla y botón. }\end{array}$ & $\begin{array}{l}\text { Clavos de } \\
\text { sección } \\
\text { cuadrangular, } \\
\text { rectangular y } \\
\text { cilíndrica; } \\
\text { bombilla. }\end{array}$ & $\begin{array}{l}\text { Proyectiles } \\
\text { de armas de } \\
\text { fuego, } \\
\text { alambres, } \\
\text { clavos, } \\
\text { herrajes, } \\
\text { varillas. }\end{array}$ & Clavos & $\begin{array}{l}\text { Clavos, pala, } \\
\text { parte de } \\
\text { arado, } \\
\text { horquillas, } \\
\text { chaira, } \\
\text { alambre, } \\
\text { bisagras, } \\
\text { mango de } \\
\text { sartén, } \\
\text { cuchara, } \\
\text { lastas y } \\
\text { contenedores. } \\
\begin{array}{l}\text { Bomba de } \\
\text { irrigación. }\end{array}\end{array}$ \\
\hline Cerámica & $\begin{array}{l}\text { Loza whiteware lisa } \\
\text { y decorada (platos, } \\
\text { tazas y bowl) y un } \\
\text { fragmento pearlware } \\
\text { decorado. Botella de } \\
\text { gres de cerveza y } \\
\text { tinta. Pipa de caolín. } \\
\text { ¿Cerámica local/ } \\
\text { indígena/africana? }\end{array}$ & \begin{tabular}{|l} 
\\
\\
Loza. \\
Cerámica de \\
pasta roja. \\
Botellas de \\
gres. \\
Pipas de \\
caolín. \\
\end{tabular} & 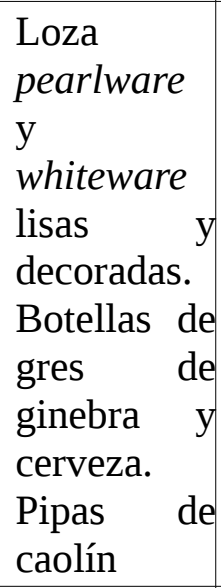 & $\begin{array}{l}\text { Lozas } \\
\text { pearlware y } \\
\text { whiteware } \\
\text { Botellas de } \\
\text { gres, frasco } \\
\text { de } \\
\text { porcelana. } \\
\text { Pipas de } \\
\text { caolín }\end{array}$ & $\begin{array}{l}\text { Loza inglesa } \\
\text { pearlware y } \\
\text { whiteware } \\
\text { (plato, bowl, } \\
\text { taza). Platos } \\
\text { de te/café de } \\
\text { porcelana. } \\
\text { Botella de } \\
\text { ginebra y } \\
\text { cerveza de } \\
\text { gres. Pipa de } \\
\text { caolín. }\end{array}$ \\
\hline Cronología & $\begin{array}{l}\text { Último tercio del } \\
\text { siglo XIX y primera } \\
\text { década del siglo XX }\end{array}$ & $\begin{array}{l}\text { Segunda } \\
\text { mitad del } \\
\text { siglo XIX }\end{array}$ & $\begin{array}{l}\text { Último } \\
\text { cuarto del } \\
\text { siglo XIX }\end{array}$ & $\begin{array}{l}\text { Segunda } \\
\text { mitad del } \\
\text { siglo XIX }\end{array}$ & $\begin{array}{l}\text { Segunda } \\
\text { mitad del } \\
\text { siglo XIX }\end{array}$ \\
\hline
\end{tabular}

Fuente: elaborado en base a Brittez, 2000, 2002, 2006, 2004, 2009; Brittez y Wibaux 2011; García, 2014; García Lerena y del Papa, 2014; Giovannetti y Lema, 2007).

El segundo sitio, Estancia Ballenera Vieja (EBV), se localiza sobre la margen derecha del arroyo La Ballenera y constituye un asentamiento rural tipo estancia establecido en la década 1830 por fuera de la línea de frontera oficial. Los restos arqueológicos hallados en estratigrafía corresponden a huesos de fauna doméstica y silvestre, loza inglesa, diversos recipientes de vidrio, gres y porcelana así como clavos, ladrillos y baldosas (Brittez \& Wibaux, 2011). Por último, el sitio Estancia Iraola (EIr), ubicado a unos pocos km del Río de la Plata, constituye un basurero doméstico de la familia Iraola que vivía en dicha estancia. El mismo presentó gran diversidad de piezas óseas, vítreas, 
cerámicas y metales. Es de destacar la evidencia de vestimenta representada por botones de camisas de diversos materiales - vidrio, asta de vaca y ciervo- y partes de zapatos de cuero femenino (Giovannetti \& Lema, 2007).

\section{La configuración y el uso del espacio rural}

\section{Los primeros ranchos}

Durante la época colonial y hasta entrado el siglo XIX, el aspecto de los primeros puestos rurales bonaerenses no había variado demasiado. No eran más que un rancho con piso de tierra apisonada -aunque algunos eran de ladrillo cocido-, paredes de barro crudo o cocido -adobe-, ventanas cubiertas por cueros y techos de paja o juncos (Figura 2). Si había un monte de ñandubay -Prosopis affinis- cerca se utilizaba la madera para armar su estructura (Moreno, 1998). Estos ranchos solían tener un solo ambiente destinado a múltiples usos -cocina, comedor, sala, dormitorio- o, a lo sumo, dos ambientes. Igualmente, la cocina podía estar agregada al rancho como una habitación aparte de la sala y del aposento (Cabrejas, 2000). Este único ambiente propiciaba el uso colectivo del espacio y de los objetos a su alcance. Según, el censo nacional de 1869, este tipo de construcciones constituían el 98,5\% de la totalidad de las viviendas que fueron relevadas en los partidos de la microrregión de estudio (Tabla 3).

Hacia el último cuarto del siglo XIX, los ranchos comenzaron a cambiar, pasando a construirse casas de material, es decir, con paredes de ladrillo, puertas de ingreso a las habitaciones, con azotea o techos de teja, como veremos más adelante. Además, las actividades desarrolladas y las funcionalidades de los mismos se fueron haciendo cada vez más específicas y se complejizaron, constituyendo una parte fundamental de la organización de las estancias locales (Reguera, 1999, 2006). Estas estancias subdividieron cada vez más sus campos, reubicando puestos de manera estratégica. Estas separaciones del espacio al interior y exterior de las mismas permitieron una organización concreta y pautada del tiempo y de las actividades así como estuvieron destinadas a ejercer el control y la vigilancia y a generar distancia social (Brittez 2006).

Figura 2. Ranchos.

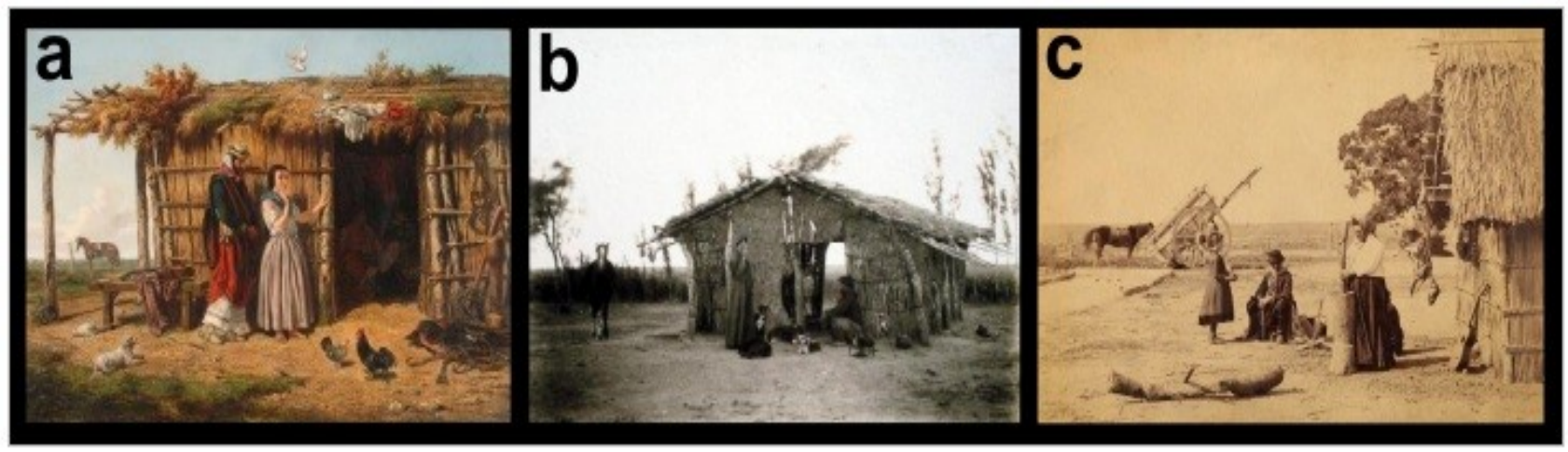

a. Óleo sobre tela, 100 x 140 cm, Idilio criollo, Juan León Pallière (1823-1887). b. Predicando, fotografía de autor desconocido,

Colección Witcomb, AGN, fines del siglo XIX. c. Pisando maíz, fines del siglo XIX. Álbum Aficionados, AGN, Inventario 213179. 
Lo anteriormente expuesto se refleja en el registro arqueológico. La ausencia de materiales constructivos duraderos en la mayoría de los puestos abordados -MO y ESI- salvo pequeños fragmentos de ladrillo artesanales en LT3, indicarían que posiblemente hayan sido erigidos con elementos perecederos. Todos estos puestos no alcanzarían el porte edilicio que suponemos para V2 y los ubicados en la cercanía de LL. Según las fotografías tomadas por Teófilo Gomila (Figura 3), los puestos que existieron en relación con la estancia LL tuvieron una importante envergadura edilicia con paredes de material, techos de chapa o tejas, varias habitaciones, etc., con sectores aledaños arbolados y parcelados para corral de animales, huerta y/o agricultura. Es posible que V2 sea similar a estos debido a la gran presencia y diversidad de elementos constructivos hallados siendo destacable las cerámicas nacionales -ladrillos- e importadas, entre ellas, distintas variantes de tejas de la marca Pierre Sacoman y variedades de baldosas de las marca Marsella y Guichard (Brittez, 2002).

A partir de este estudio, es interesante analizar las características y funcionalidades que los puestos rurales pudieron tener como parte de las estancias en el área a lo largo del tiempo y sobre todo, en las últimas décadas del siglo XIX, considerando no sólo los casos arqueológicos mencionados sino también distintas fuentes citadas por historiadores (Cabrejas, 2000; Mayo, 2000; Reguera, 1999, 2006; Sábato, 1989; etc.). Estos puestos rurales comenzaron siendo unidades productivas de tipo pastoril cuyos habitantes primero se dedicaron a la explotación extensiva del ganado vacuno -como en el caso de LT3- y luego, a la cría de ovinos. También a tareas agrícolas a pequeña escala y para el sustento familiar. Estos campesinos generalmente no eran propietarios de la tierra, dependían de la fuerza de trabajo familiar y poseían cierta capacidad de acumulación (Reguera, 1999). Posteriormente, la demanda nacional y extranjera de productos ganaderos, el alza de los precios de los mismos, la disponibilidad de nuevas tierras, la especialización e intensificación productiva, entre muchos otros factores; consolidaron a la estancia como unidad productiva agrícola-ganadera y base para dicha expansión acorde al proyecto nacional y afianzamiento en el mercado mundial. Dentro de estas estancias existía un número de trabajadores permanentes y otros temporarios, que se integraban a las mismas de manera ocasional y/o estacional, constituyendo la población que habitaba estos puestos.

Tabla 3. Tipos de casas relevadas en los partidos de Necochea, Juárez y Tres Arroyos en el censo nacional de 1869

\begin{tabular}{|l|l|l|l|l|l|l|l|l|l|}
\hline \multirow{2}{*}{$\begin{array}{l}\text { Tipo de casa } \\
\text { Partido }\end{array}$} & \multicolumn{3}{|c|}{ Casa con Azotea } & \multicolumn{2}{l|}{ Casa de Teja } & $\begin{array}{l}\text { Casa } \\
\text { Madera }\end{array}$ & \multicolumn{2}{|l|}{$\begin{array}{l}\text { Casa de } \\
\text { Paja }\end{array}$} & Total \\
\cline { 2 - 12 } & 3c & 2c & 1c & 2c & 1c & 2c & 1c & 1c & \\
\hline Necochea & - & - & - & - & - & - & - & 242 & 242 \\
\hline Benito Juárez & - & - & 6 & - & - & - & 4 & 302 & 312 \\
\hline Tres Arroyos & - & - & - & - & - & - & - & 144 & 144 \\
\hline Total & - & - & 6 & - & - & - & 4 & 688 & 698 \\
\hline
\end{tabular}

Fuente: http://www.santafe.gov.ar/archivos/estadisticas/censos/C1869-TU.pdf, pp. 86-87. Nota: La letra c corresponde a cuerpo.

En este último contexto, cuando hablamos de puestos rurales nos referimos a puestos ganaderos y/o 
chacras agrícolas con características y funciones cada vez más pautadas y específicas. Los primeros, dedicados a la cría y explotación de vacas y ovejas, con un predominio del lanar e invernada de carneros. Las segundas, orientadas a la producción agrícola de forrajeras y cereales con fines de exportación y para el abastecimiento interno de la estancia junto con las quintas. También cultivaban el alimento de los distintos animales: maíz para las gallinas, chanchos y pollitos, avena y cebada para carneros y novillos, alfalfa para los toros, etc. Además, se dedicaban a la plantación forestal para la producción de leña necesaria para el funcionamiento de las maquinarias, calentamiento de las marcas de yerra, para cocinar y como postes de los alambrados (Reguera, 1999). En este sentido, la funcionalidad de todos los puestos abordados desde la arqueología en este artículo se relacionaría con actividades productivas, sobre todo agrícola-ganaderas en las distintas áreas bonaerenses donde se hallaban emplazados. Los puestos rurales en el espacio fronterizo y rural pampeano han tenido un papel sumamente importante en la realización, mantenimiento y control de actividades concernientes a la producción agro-ganadera inicial de la microrregión, así como también en la circulación de bienes y productos nacionales y extranjeros que generaron con nuevas necesidades y hábitos de la vida cotidiana.

La ocupación efectiva por parte de la población criolla, la localización estratégica de los puestos cercanos a fuentes de agua como, por ejemplo, la laguna Las Toscas, el arroyo Pescado Castigado o el Río de la Plata, los incipientes caminos que originaron futuras redes como los que figuran en los duplicados de mensuras antes citados en nuestro caso -p.e. camino de Tres Arroyos, camino del Tandil al Cristiano, camino de Necochea a Juárez, etc.-, la parcelación del terreno para la ganadería o la agricultura, entre muchos otros elementos; impulsaron una transformación del paisaje en el sur bonaerense. Con el paso de las décadas, la consolidación de los primeros puestos criollos y la complejización de las actividades y circuitos productivos y comerciales configuraron un nuevo paisaje rural, diferente al establecido hasta el tercer cuarto de siglo XIX. Este nuevo panorama rural implicó la instalación de asentamientos de mayor envergadura, no sólo edilicia sino en relación con las actividades y funciones que allí se realizaban. La multiplicación de estos puestos, luego absorbidos por las estancias rurales, sumados a los comercios rurales y un aumento en el número y densidad de la población -como lo indican los censos nacionales de 1869 y 1895 y, el censo provincial de 1881- fueron conformando lentamente, junto con las redes viales y la llegada del ferrocarril, los primeros pueblos del sur bonaerense. En la microrregión de estudio entre 1885 y 1886 se extendió la línea de ferrocarril "Ferrocarriles del Sud" desde Tandil a la ciudad de Tres Arroyos pasando por los partidos de Juárez y Gonzales Chaves; creándose, a su vez, los pueblos de Juárez y Tres Arroyos en 1874 y 1885, respectivamente. Los pueblos de Gonzales Chaves (1906) y San Cayetano (1911) se fundaron posteriormente. 
Figura 3. Puestos de la estancia LL.

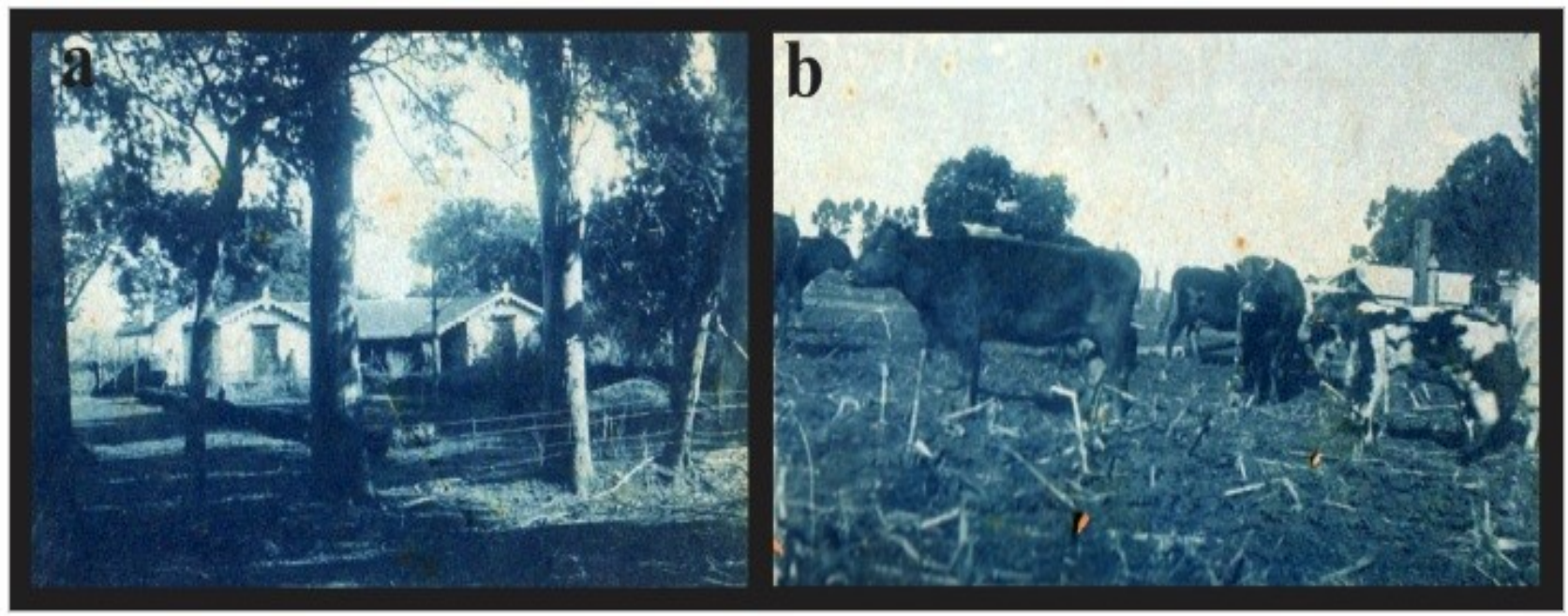

a. Puesto Las Martinetas. b. Puesto Colorado (fotografías de T. Gomila, 1899, gentileza de V. Satas).

Para el caso de Tres Arroyos, Mulazzi (1938) destaca que hasta entrada la década de 1860, el partido constituía un territorio fronterizo con escasos pobladores: “...no hay familias establecidas [habiendo] hombres solos en las poblaciones” (Mulazzi 1938:44). Pero hacia fines de 1870 Gorraiz estima que el partido estaría ocupado “de extremo a extremo" y con miles de cabezas de ganado (Gorraiz 1935:75). En este sentido, según el censo de 1881, Tres Arroyos era casi exclusivamente un partido ganadero existiendo únicamente 25 hectáreas cultivadas (contrariamente a lo que sucede actualmente). La mayor parte de las tierras eran ocupadas por 1.521 .240 lanares seguidos por 353.941 vacunos, 93.212 yeguarizos y 552 porcinos (Levene 1941:693). Esta tendencia de alguna manera ya se visualizaba en el censo anterior, que registró 82 hacendados, 175 peones, 65 capataces, 42 jornaleros y únicamente dos agricultores. Por último, para 1895 se presentó un núcleo urbano constituido por el 35,8\% de los habitantes de la totalidad partido (Gorraiz 1935).

\section{La espacialidad en la estancia bonaerense: nuevas actividades, órdenes y controles}

Hacia mediados del siglo XIX en la pampa húmeda, comenzaron a gestarse una serie de cambios sociales y económicos de la mano de la modernización, la industrialización y el capitalismo que condujeron a la sociedad fronteriza bonaerense a transformarse en una sociedad agrícola-ganadera moderna hacia fines de dicha centuria. Estas transformaciones se dieron en forma gradual e implicaron el paso de la estancia de frontera a una empresa rural, de una ganadería extensiva a una ganadería intensiva con trabajo a corral y de la cría y explotación del ganado bovino a la de ganado ovino (Brittez, 2006; Reguera, 2006; Sábato, 1989; Sesto, 2005; Zebeiro, 1999). De esta forma, la construcción, la infraestructura y el funcionamiento de los espacios en los asentamientos tipo estancia variaron a lo largo del tiempo en la provincia de Buenos Aires (Brittez, 2006). Primeramente denominamos estancia a los establecimientos rurales productivos de cierta escala, cuya organización fue cambiando desde la primitiva estancia colonial dedicada a la producción de cuero vacuno hasta la actual empresa productora de cereales y ganado refinado como las estancias LL, EIn y EBV en el sur bonaerense (Brittez, 2006:91; Sábato, 1989:133). 
La historiadora A. Reguera (1999, 2006) establece un esquema de relaciones y funcionamiento (Figura 4) dentro de las estancias bonaerenses para la segunda mitad de siglo XIX tomando el caso del pionero terrateniente Ramón Santamarina, propietario de tierras en distintos partidos de la provincia de Buenos Aires, entre ellos algunos de nuestra área de estudio. La estancia como unidad productiva agrícola-ganadera con orientación al mercado se encontraba compuesta de un casco principal de material donde habitaba el estanciero y su familia así como en algunas también el mayordomo y su familia. Contaba con determinada infraestructura -puestos, chacras, corrales, galpones, aguadas- y tecnología -alambrado, maquinarias, arado, carros- que produjeron una modificación del paisaje rural. A pesar de vender/exportar gran parte de lo que producía, una porción estaba destinada al autoconsumo. El control del trabajo estaba a cargo del mayordomo y se registraba diariamente en libros. La organización de las actividades era dictada por los capataces y las llevaban a cabo los chacareros, puesteros y peones. A su vez, el mayordomo regulaba el intercambio de bienes y productos entre las chacras y los puestos. Las chacras agrícolas, además de trigo y avena, producían alimentos para los animales domésticos, en tanto los puestos se dedicaban a la producción ganadera, fundamentalmente vacuna y ovina. El chacarero era socio capitalista del estanciero, al igual que el puestero, en la producción existiendo distintos tipos de contratos. El estanciero era el propietario de la tierra y ponía parte del capital aunque tanto el chacarero como el puestero tenían acceso a la explotación y parte de las ganancias, pero en distintas proporciones. Asimismo, estas estancias disponían de un número fijo de trabajadores permanentes y otros estacionales con empleo temporario. Se calcula que una "suerte de estancia” (2.025 ha.), podía alimentar a pasto natural entre 800 y 1000 cabezas de ganado vacuno de cría (Reguera 1999).

Figura 4. Esquema de relaciones laborales y sociales dentro de la estancia de fines de siglo XIX desarrollado a partir de la propuesta de Reguera (1999).

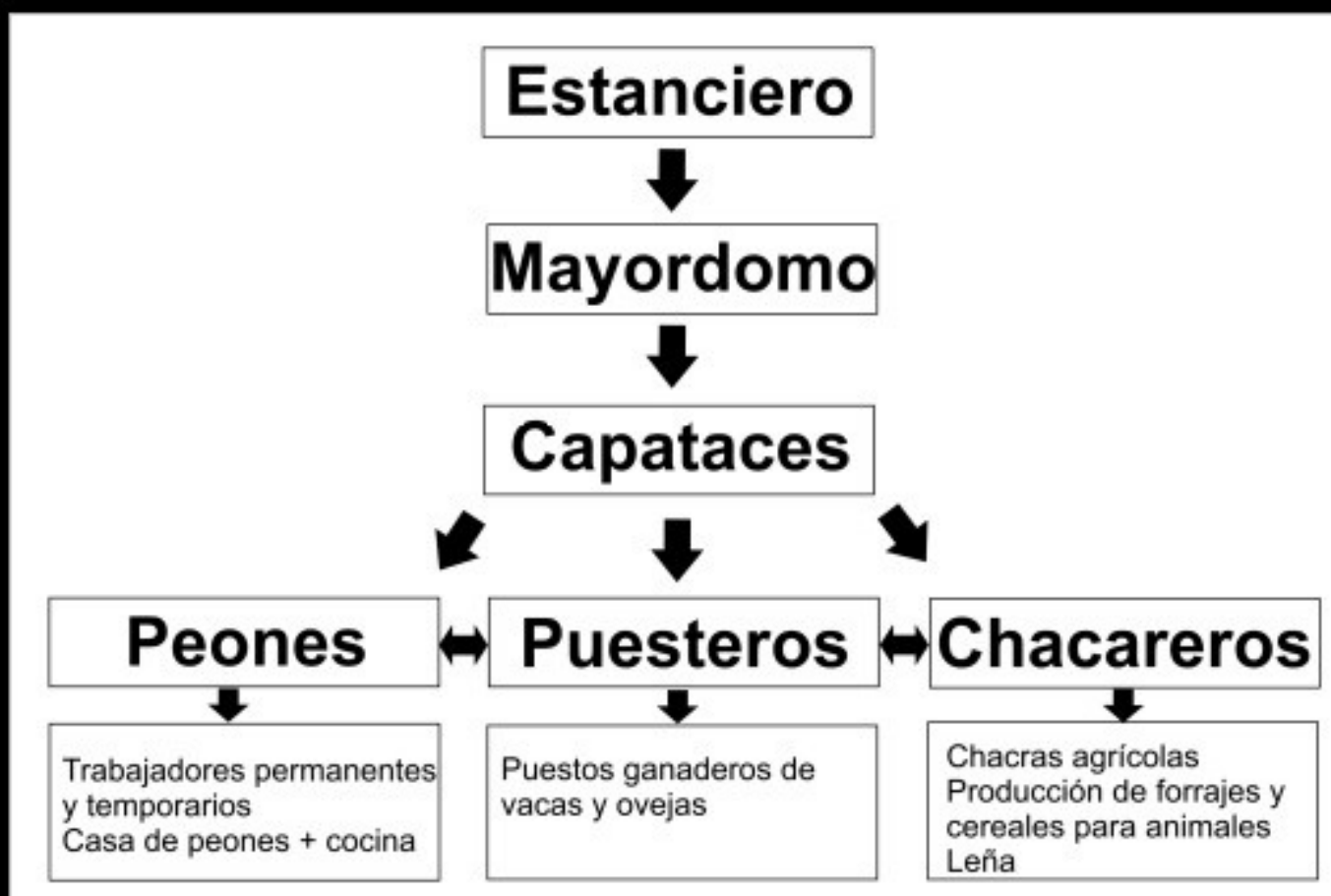


A partir del registro arqueológico y escrito recuperado para el sitio LL, es que pensamos que este esquema se estaría dando en la misma a fines de siglo XIX. Los restos óseos hallados en dicha estancia evidencian la producción y explotación de vacunos, lanares y animales domésticos de mejor jerarquía como nos referiremos más adelante (Bagaloni \& Carrascosa Estenoz, 2013). Asimismo, los numerosos documentos escritos y gráficos dan cuenta de la siembra y cosecha de trigo y avena, entre otros (Bagaloni, 2010, 2014a). Por otro lado, las numerosas fotografías y menciones de puestos en las cartas y el testamento de Gomila demuestran que la estancia contaba con mayordomo, capataces, puesteros, chacareros y peones (Bagaloni, 2014a; de Jong \& Satas, 2011; Archivo fotográfico Gomila en posesión de V. Satas). Esta tendencia también se evidencia tanto por la documentación escrita como por los materiales arqueológicos hallados en el caso de EIn y EBV. En este último sitio, distintas fuentes escritas revelaron una organización espacial del establecimiento productivo constituida por una estructura edilicia principal de material (por lo menos ya en 1870), una quinta y tres puestos -La Totora, La Carolina y de la Costa- a cargo del manejo de la hacienda vacuna y lanar (Brittez \& Wibaux 2011: 365).

Por otro lado, desde mediados de este siglo, se concreta, una disposición y uso del espacio diferente al que se daba anteriormente, caracterizado por parcelas separadas y con funciones específicas, donde convivían distintos sectores sociales y culturales y donde se fueron estableciendo nuevas normas laborales mediante el disciplinamiento de la mano de obra rural (Brittez, 2004, 2006; Sesto, 2005). La introducción del alambrado (1845) propició la sectorización y compartimentación del espacio dentro la estancia, generando un ordenamiento pautado de las actividades y de las cosas dentro de la misma (Brittez, 2006; Moreno, 1998; Sbarra, 1964). El uso del alambre no sólo implicó un paso tecnológico asociado al cambio en la espacialidad de la estancia, sino que estuvo acompañado por un cambio en las pautas laborales y las relaciones sociales. Los campos, parcelas y potreros ahora divididos mediante alambrados permitieron un mayor control y cuidado de los sembrados y animales, así como una diversificación de la producción y de las tareas desarrolladas. La implementación de tecnología para la siembra y la cosecha también constituyó un avance importante -p.e. fotografías de sesgadora y trilladora de Gomila en Bagaloni, 2014a-. El alambrado proporcionó, además, un control de los accesos mediante puertas y tranqueras en distintos lugares de la estancia debiendo, tanto el visitante como los trabajadores pedir permiso para poder ingresar a determinados sectores -p.e. casa de los puesteros, el casco y sus alrededores, etc.- (Moreno, 1998).

La estancia LL fue una de las pioneras del partido en adquirir la tecnología del alambrado en 1880 según carta del propio Gomila (Bagaloni 2014a; de Jong \& Satas, 2011). Ya se han comentado los numerosos fragmentos de alambre así como las distintas piezas de metal pertenecientes a tranqueras que forman parte del conjunto arqueológico allí recuperado. El registro documental y arqueológico indicarían, además, que la construcción del casco de LL se realizó con materiales de buena calidad para la época: ladrillos cocidos, pisos de madera en las habitaciones, baldosas y azulejos franceses, rejas de metal en las puertas y ventanas, conformando ambientes diferenciados tanto para los propietarios como para la familia del mayordomo y los peones, entre otras características que marcaban status y cierto grado de riqueza. De igual forma, hacia fines de la década de 1860, una fotografía de la EIn registra que estaba conformada por un gran rancho de adobe y paja pero desde 1873 en adelante se construyó una instalación de material -p.e. ladrillos cocidos, azulejos Pas de Calais, baldosas Leon Duplessy de Havre, pisos de madera, etc.- que evidencia cierta calidad en la 
edificación y poder adquisitivo de sus habitantes en esa época que sugiere "un rápido ascenso económico de los estancieros” (Brittez, 2006:103). Brittez (2006) realizó un estudio detallado de distintos manuales agropecuarios publicados entre 1881 y 1908 con una serie de instrucciones para estancieros y tomó como ejemplo arqueológico el caso de EIn. En estos manuales se delinea cómo debía ser el diseño, orden y funcionamiento del espacio dentro de las estancias bonaerenses para un óptimo manejo y control de las tareas laborales y actividades cotidianas. Por ejemplo, el casco debía estar ubicado preferentemente en el centro o en una esquina, nunca sobre un lado del campo como se daba en los establecimientos de frontera, para una mejor vigilancia por parte del patrón o del mayordomo. La presencia de un mangrullo también era propicia para observar las haciendas y las actividades llevadas a cabo por los peones y puesteros. Asimismo, el casco debía tener una serie de condiciones que propiciaran la distancia social entre los diferentes grupos sociales. En este sentido, era oportuna la presencia de dos cocinas, una para el estanciero y su familia y otra para los peones. La estancia LL justamente se localiza en una esquina del campo, cuenta con una torre de observación o mirador (ver Figura 6.40a en Bagaloni, 2014a) en el propio casco así como con dos cocinas, orientadas posiblemente de norte a sur, como lo señalan las dos chimeneas registradas en distintas fotografías de época de la misma (ver Figura 1 en Bagaloni \& Carrascosa Estenoz, 2013:378). También la presencia de un patio en el interior del casco permitió a Gomila y su familia desarrollar diferentes actividades en absoluta privacidad -p.e. comer un asado como se observa en la Figura 5a más adelante-.

\section{La explotación de animales domésticos y la alimentación rural}

El paso de la ganadería extensiva a campo abierto a una producción ganadera de carácter intensivo dentro de un marco de capitalismo industrial regional así como las transformaciones sociales y económicas que conllevaron han sido abordados arqueológicamente. Este cambio en cada puesto o estancia se vio condicionado por el lugar de instalación del establecimiento dentro del territorio bonaerense, por el avance de la frontera y la conformación de los pueblos, por la cronología de ocupación de los mismos, por los procesos que los afectaron particularmente, es decir, por las microhistorias de sus habitantes donde, algunos de ellos han tenido gran envergadura a nivel provincial -p.e. Teófilo Gomila- o nacional -p.e. Martín Iraola-; así como por el acceso y la implementación de tecnologías y la cercanía a comercios minoritas que los ubicaron en variados y distintos circuitos de abastecimiento y consumo. Es decir, estos cambios en la producción agrícola y ganadera no se dieron en todas las áreas al mismo tiempo y de la misma forma, por lo menos, en la provincia de Buenos Aires.

Desde los puestos fronterizos iniciales -como LT3, MO- hasta las estancias especializadas -LL, EIn, EIr, EBV- con sus puestos rurales -V2, ESI- destinadas a la explotación de ovejas, nos encontramos con diversas tendencias arqueofaunísticas e hipótesis sobre los modos de funcionamiento interno. En los primeros puestos, se registró cierta diversidad taxonómica de fauna doméstica y silvestre, que comprende fundamentalmente mamíferos (vaca, oveja, caballo), armadillos, roedores y aves. En el sitio LT3 las huellas antrópicas de cuchillo detectadas fundamentalmente en vaca y oveja corresponden a distintas etapas del procesamiento de una carcasa, incluyendo cuereo, desarticulación y fileteo indicando su consumo de forma hervida o asada. En MO también se 
hallaron huellas de corte en armadillos. Tanto en las estancias tardías como en los posibles puestos asociados a éstas se detectó un conjunto faunístico más definido con una amplia diversidad taxonómica caracterizada por un mayor número de animales criados domésticamente (principalmente oveja aunque también vaca, caballo, gallina, pavo, cerdo, perro, gato) sobre los silvestres. Asimismo, posiblemente se practicaba la pesca, la caza de aves silvestres, armadillos, roedores, liebre y la recolección de huevos de ñandú.

A partir del estudio de las huellas de procesamiento se identificaron prácticas y hábitos en cuanto a la preparación y consumo de los alimentos así como preferencias en la dieta rural. La cantidad, variedad, distribución y frecuencia de huellas de corte, corte y golpe y aserrados son indicios de distintos patrones y niveles de trozamiento, así como de las diferentes fases de obtención, preparación y consumo de los alimentos con gran aporte cárnico. En el caso de LL, en ovejas y mamíferos medianos se dieron los tres tipos de trozamiento propuestos por Marschoff (2007). Pudo determinarse que en vacunos y mamíferos grandes el cuereo, la evisceración y la desarticulación primaria se desarrolló posiblemente en lugares cercanos a los puestos ganaderos (p.e. en los puestos Colorado o Las Martinetas) siendo el espacio de cría de los mismos y no en el casco principal. A este estarían ingresando determinados “cortes” (exclusivamente se registraron evidencias de corte con cuchillo, hacha y sierra en costillas y vértebras de Bos taurus) para el consumo de la familia Gomila, la familia del mayordomo y el resto de los empleados domésticos del casco. Mientras que para el caso de Ovis aries y mamíferos medianos, en base a la evidencia arqueológica sostenemos el desarrollo de actividades de trozamiento primario, secundario y terciario, y además, por el registro fotográfico suponemos que las ovejas se hallaban en corrales cercanos a la casa principal (ver Figura 7a en Bagaloni \& Carrascosa Estenoz, 2013). También se consignaron huellas de cuchillo en peludo, cánido, gallina y otras aves. No obstante, para el puesto ESI, García Lerena y del Papa (2013:31) proponen que el casco principal contaba con corrales vacunos y que la representación diferencial -fundamentalmente miembros y costillas de Bos taurus- se debería a que en el casco se desarrollaron las tareas de matanza, despostamiento primario y distribución hacia los puestos rurales y en estos se estaría dando in situ el faneamiento así como el consumo de los ovinos. De igual forma, más allá de cómo se dio la circulación dentro de cada establecimiento, tanto para LL como para ESI, se evidencia el consumo por parte de todos sus habitantes de partes ovinas y vacunas de alto rinde cárnico. En todas las estancias estudiadas se destaca una gran infraestructura en función de la cría, explotación y consumo de animales domésticos de manera intensiva, “a corral”, sobre todo del ganado ovino por sobre el vacuno, afirmando las tendencias de la época (Brittez, 2000, 2006; Reguera, 2006; Sábato, 1989). Éstos ganados eran colocados en mercados regionales y nacionales así como constituían parte del abastecimiento rural local. Cabe aclarar que en EIr se halló gran cantidad de restos de oveja, caballo y vaca con huellas de corte producto del consumo humano de carne pero que aún su estudio no ha sido publicado (Giovannetti \& Lema, 2007: 89; Bogan comp. pers. 2017).

Los trabajos de Brittez constituyen estudios pioneros sobre los patrones de consumo rurales tardíos bonaerenses (Brittez, 2000, 2009; Brittez \& Wibaux, 2011). Los distintos sitios arqueológicos (puestos y estancias así como militares) de la segunda mitad del siglo XIX estudiados por este autor, tanto del sur bonaerense como el resto de la provincia mostraron tendencias generales y similares: 1) la prevalencia de la explotación y consumo de ganado ovino por sobre los vacunos coincidiendo 
con la denominada “fiebre del lanar” entre 1840 y 1880 (Sábato, 1989), 2) la preferencia de la carne ovina y bovina, por su bajo costo y abundancia, pero complementada con aves de corral y fauna silvestre, 3) la representación menor del cerdo en la dieta rural, 4) la importancia relativa de la oveja fue decreciente de los sitios productivos a los militares, aunque en el caso de los vacunos se observó la relación inversa, 5) la nula o baja presencia de liebre, perdiz y ñandú discrepando con las fuentes documentales. Además, se destacan algunos aspectos comunes en el estudio arqueofaunístico de los sitios rurales tales como los problemas de muestreo, los distintos enfoques arqueológicos así como estados disímiles de avance en las investigaciones; la falta de estudios de procesos de formación de los sitios, tafonómicos y experimentales, la preservación diferencial de restos de fauna doméstica y silvestre -debido al tamaño y densidad de los huesos de los primeros-, la destrucción por ingesta de elementos óseo de pequeño porte por parte de carnívoros domésticos como el perro, el pisoteo de ganado, la presión y destrucción por parte de las máquinas agrarias y viales; los episodios de quema de basureros para el control de olores, entre muchos otros (Brittez, 2009).

En líneas generales, los puestos tardíos y estancias abordados en este trabajo coinciden a grandes rasgos con estas tendencias. Sin embargo, el hallazgo de algunas especies como Sus scrofa y Rhea americana, y la familia Canidae en LL ha sido de gran importancia ya que hasta el momento no se habían descubierto en los conjuntos arqueológicos de instalaciones agropecuarias en contextos rurales del sur bonaerense de la segunda mitad del siglo XIX, como los sitios EIn y EBV (Brittez, 2000, 2009; Brittez \& Wibaux, 2011). En el caso de ESI es relevante la presencia de cáscaras de huevo de ñandú para el este bonaerense. En cambio, se encontraron restos óseos de cerdo, ñandú y perdiz en otros asentamientos rurales como los distintos fortines de la frontera Sur y Costa Sur. La liebre europea que aparece en LL, V2 y LT3 debe ser analizada con cautela en este último sitio, ya que la misma fue introducida en el norte de la provincia de Buenos Aires recién a fines de siglo XIX (Brittez \& Wibaux, 2007). A medida que se amplíen los estudios de los distintos registros de sitios rurales, así como se profundice la indagación sobre los distintos procesos depositacionales y postdepositacionales que los afectaron, tendremos un panorama más acabado de las elecciones y patrones de consumo de los pobladores rurales del siglo XIX.

Por otro lado, estas especies animales estarían entrando a la mesa rural de manera asada -a la parrilla o al asador- y/o hervida, por lo menos, así lo evidencian los fragmentos de oveja y vaca termonalterados -parcialmente quemados y quemados- y con fractura fresca en LL y en ESI, (Bagaloni \& Carrascosa Estenoz, 2013; García Lerena \& del Papa 2013). Igualmente, los restos de estas y otras especies que se encontraron calcinados pudieron haber sido descartados en fogones para ser usados como combustible -LL, LT3- y/o basureros -V2, LT3, MO- o simplemente descartados al fuego -p.e. en ESI-. Por otro lado, en LL la presencia de un gran número de mandíbulas y huesos largos con fracturas transversales y longitudinales a la altura de la diáfisis respondería a la obtención de la médula ósea (caracú). Estas fracturas podrían deberse a prácticas de trozamiento terciario para reducir las porciones cárnicas ya sea para asarlas o para que entraran en una olla. Otro modo de cocción de estas carnes en los puestos y estancias rurales estudiadas fue sin duda en forma de puchero, guisado o preparaciones hervidas similares. Silveira (1999: 402) destaca que en este tipo de cocción de larga duración, donde la carne se separa fácilmente del hueso, es bajo el porcentaje de huellas de corte que pueden quedar plasmadas en los elementos óseos. En cuanto al registro documental, para LL contamos con una fotografía tomada en enero de 1899 por Gomila, se 
observa a tres de sus hijos comiendo un costillar de asado cocinado bajo un árbol en el patio de la estancia (ver Figura 5a más adelante).

Una dieta fundamentalmente proteica habría sido común para los distintos sectores de la población rural. La desigualdad no estuvo quizás en el qué sino se acentúo en el cómo. Es decir, las diferencias no se dieron tanto en el tipo de cortes a los que tenían acceso los distintos pobladores rurales, desde el estanciero y el mayordomo con sus respectivas familias hasta los peones de campo. Sino que los hábitos de mesa y la cultura material asociada a los mismos constituyeron la distinción: la cantidad y calidad de vajilla de loza, porcelana y vidriería importada con funciones específicas, la diversidad de elementos para la preparación de las comidas, el consumo de determinadas bebidas finas, etc.; prácticas ligadas a variados rituales, conductas y gustos que marcaron una sofisticación en los modos de comer. Ésta, a su vez, se vio directamente relacionada con el status social de la clase a la cual el habitante rural pertenecía. De esta manera, se impulsa una toma de conciencia y construcción del status por parte de estos pobladores, así como una exhibición y reproducción del mismo para legitimarlo (Bagaloni, 2014a).

\section{Dieta y hábitos de consumo en la mesa rural bonaerense}

A mediados del siglo, las ventajas proporcionadas por la Argentina, entre ellas, sus características ecológicas, la abundancia de tierras, la mano de obra, el sistema de comunicaciones y el marco jurídico y legal, permitieron su ingreso al mercado capitalista mundial. Europa encontró una plataforma para alimentar a su población y abastecer a su industria con materias primas a bajo costo provenientes de nuestro país y del resto de Latinoamérica. Así se produce la integración de la pampa bonaerense a la economía mundial siguiendo las reglas del mundo capitalista en crecimiento cada vez más tecnificado e industrializado (Hobsbawm, 1998; Zeberio, 1999). Esto permitió la importación masiva al Río de la Plata de variados artículos que pasaron a formar parte del stock de las casas de negocio y pulperías de las zonas rurales, en detrimento de los productos regionales y mercancías del país, desde la segunda mitad del siglo XIX (Carrera, 2004, 2014; Correa \& Wibaux, 2000; Mayo, 1996, 2000, 2007; Wibaux, 2004).

A partir de esta época surgen nuevas pautas de consumo asociadas a la modernización del mundo rural dadas por "la expansión de circuitos comerciales, cambios en las vías de transporte y aprovisionamiento de mercancías, y consolidación de los núcleos de asentamientos rurales” (Brittez \& Wibaux, 2007:5). De esta forma, el espacio fronterizo/rural conformó una red de asentamientos y comercios influenciados local y regionalmente por la modernización y el capitalismo industrial emergente (Brittez, 2000). Este cambio impactó en la vida cotidiana de los pobladores fronterizos y rurales -soldados, trabajadores rurales, estancieros, indios amigos, entre otros- llevándolos a un refinamiento de sus gustos y una renovación de sus hábitos y costumbres. Esto se vio reflejado en nuevas prácticas de consumo, que a través de la diversificación en cantidad y calidad de los artículos ofrecidos en las casas de negocios y pulperías, permitieron el acceso por parte de los diferentes sectores sociales (Carrera, 2004, 2014; Mayo, 2000, 2007; Wibaux, 2004). Asimismo, la importancia de las casas de negocio, pulperías y otros comercios minoristas rurales como Chapar (Bagaloni, 2014a, 2014b) o la que funcionó dentro de la estancia LL (Bagaloni, 2014a), no solamente radica en el abastecimiento de los habitantes de la frontera o del espacio rural 
con alimentos y demás elementos necesarios para la subsistencia (herramientas, vestimenta, “vicios”), sino que también eran espacios de entretenimiento y ocio así como importantes centros de comunicación y fuentes de información social y política (Carrera, 2004; Mayo, 2000; Wibaux, 2004).

Según información aportada por los inventarios de casas de negocios y pulperías de frontera, podemos pensar que se produjo un paulatino descenso de los productos regionales y del país -p.e. yerba amarga y suave, pasas blancas, negras y moscatel, sal, vejiga de grasa, alcaparras, azafrán, orégano, azúcar del Paraguay, jamón, carne de chanco, etc.- a favor de otros, en su mayoría, importados -café en rama, en grano, molido; té negro, perla; confites; chocolates; dulce de membrillo; frutos secos como almendras y ciruelas; harinas de trigo y maíz; fariña; pan, galleta, bizcochos, ticholos, masitas y tortas; conservas españolas; aceitunas, sardinas y bacalao-. Igualmente, hubo artículos que se mantuvieron en la dieta fronteriza y que mejoraron sus calidades, como la yerba, el azúcar, el arroz, los fideos, los condimentos, el aceite y el vinagre. No sucedió lo mismo con las legumbres, verduras, el queso y los huevos cuya aparición en los estantes de las almacenes de campo fue cada vez más limitada (Carrera, 2004; Mayo, 2000, 2007; Wibaux, 2004). Dentro de las bebidas, las alcohólicas se encuentran en mayor número y variedad, siendo las más representativas la ginebra, la caña, el aguardiente, el vino carlón y el seco, vinos cuyanos, el coñac y el anís. Aunque después de mediados de siglo XIX comenzaron a aparecer vinos españoles -Málaga, catalanes- y de Burdeos, oporto, jerez, Bitter, cerveza inglesa, ginebra holandesa, sidra, licor francés, kirsch y curazao (Carrera, 2014; Correa \& Wibaux, 2000:78; Wibaux 2004). También apoya esta tendencia el registro arqueológico de Chapar con su variedad de tipos de recipientes de distintas características materiales, origen y cronología (Bagaloni, 2014a) y de la pulpería Casa de Negocio con la presencia de una gran diversidad de objetos -botellas de vidrio, lozas europeas, porcelanas, pipas de caolín- que evidencian el comercio ultramarino en el sur bonaerense (Brittez \& Wibaux, 2007).

Desde épocas coloniales, en la mesa fronteriza y rural los comensales acostumbraban a servirse de la misma fuente u olla, a compartir los mismos utensilios -p.e. cucharas y vasos-, a comer con las manos ayudados con el cuchillo y/o a tomar del mismo mate. El mate era una de las bebidas más populares y colectivas en la frontera y en el ámbito rural. La presencia de una bombilla en ESI indica que este hábito compartido se mantuvo en el tiempo. Tanto la práctica de tomar mate como el acto de beber se consideraban una actividad separada de la comida y una ocasión para fomentar las relaciones sociales y personales (Carrera, 2004; Mayo, 2000). Este tipo de hábitos comunitarios de alimentación resultaron llamativos a los ojos de distintos viajeros que recorrieron la llanura pampeana, por la falta de intimidad a la hora de comer, los modales pocos elegantes y la falta de higiene en la preparación y consumo de los alimentos (Correa \& Wibaux, 2000). Con el boom del mercado industrial, no sólo entraron nuevos productos sino novedosas formas de servir y nuevos gustos a las mesas rurales. Así comenzó el paso de lo colectivo hacia lo individual, es decir, cada individuo fue haciendo propio el espacio cotidiano destinado a la mesa y los elementos mediante los cuales realizaba el acto de comer. Ya no se compartían los utensilios sino que cada comensal tenía su plato, sus cubiertos, su vaso, etc. Esta idea se ve apoyada por numerosos inventarios de pulperías (Carrera, 2004; Mayo, 2000, 2007; Wibaux, 2004), en las cuales se observa la creciente presencia de tazas, platos -comunes, hondos y de postre-, pocillos y platos de café, juegos de cubiertos, copas 
y vasos de cristal, jarras, teteras, máquinas y molinillos de café, chocolateras, calentadores, braseros de hierro, sartenes, saleros, entre otros.

Por otro lado, este nuevo panorama contribuyó en la construcción de una conciencia de status social y en la exhibición del mismo por parte de los sectores altos y medios, dado por el uso de determinados objetos así como por el consumo de determinadas bebidas y alimentos (Mayo, 2000; Wibaux, 2004). Según Correa y Wibaux (2000), los testimonios de viajeros relatan aspectos del consumo cotidiano de los habitantes fronterizos, dando cuenta de la división temporal de las comidas diarias en desayuno, almuerzo, merienda y cena, sobre todo en las estancias de alto poder adquisitivo. En éstas se adquirieron costumbres europeas, mayormente inglesas, donde los horarios, la vajilla y el modo de servicio se hallan claramente pautados. Sin embargo, existían eventos disruptivos de los hábitos y comportamientos cotidianos que alteraban la preparación y el consumo de los alimentos, tales como las conmemoraciones patrias, fiestas tradicionales y religiosas o momentos específicos del calendario productivo, como por ejemplo, la yerra (ver relato de Armaignac sobre la yerra en Correa y Wibaux, 2000:43). En estas reuniones se conformarían espacios públicos de alimentación que no se limitaban sólo al núcleo familiar sino que incluían a peones, capataces, vecinos, personal doméstico, amigos, viajeros, etc.

Arqueológicamente, a nivel local y regional, los habitantes de las estancias y los puestos rurales abordados en este artículo no fueron ajenos a estos cambios y su registro material lo refleja claramente. En estos sitios se identificaron ciertas tendencias generales para la segunda mitad del siglo XIX (ver Tablas 1 y 2), tales como: 1) el uso de vajillas de lozas inglesas del tipo pearlware y whiteware; 2) botellas de vidrio de variados contenidos y procedencias: vino y champagne francés, ginebra holandesa, cerveza inglesa, hesperidina de fabricación nacional, Bitter, licor; jerez español, entre otros; 3) otros recipientes vítreos como vasos, tarros de comestibles, tarros y frascos de perfumería y/o farmacia; 4) botellas de gres de ginebra holandesa así como botellas de cerveza y tinteros ingleses; 5) utensilios y contenedores de metal; y 6) en algunos casos, vajilla y objetos de porcelana europea. La diferencia entre los ocho sitios comparados radicó en la diversidad, calidad y cantidad de los elementos vítreos, cerámicos y de metal descubierto en cada uno, de manera creciente desde los primeros puestos hasta las estancias.

La vajilla de mesa de LL se presentó con una variedad de formas, tamaños y motivos decorativos de los dos tipos de lozas similar a la hallada en EIn, EBV y EIr así como en V2. Se identificaron tazas, platos, fuentes, bowls, jarro, bacín tanto lisos como con decoración pintada, transferida o impresa anular, floral, flecos, entre otros. Asimismo, en LL se halló un fragmento de loza de la marca Boch Fréres de Luxemburgo (Bélgica) fabricadas durante el siglo XIX y en EIr otro resto con el sello de la fábrica Cochram (Glasgow, Inglaterra). El servicio de porcelana solamente se consignó en las estancias representado por tazas y platos de té/café en LL y en EIr, y un frasco para EBV, siendo baja su proporción en relación con la vajilla de loza y constituyendo un claro indicador de status social debido a su alto costo. El plato de porcelana de EIr presenta el sello de un bazar porteño -“Bazar Colón, calle Piedad 145-149, Buenos Ayres”- que se estima comenzó a funcionar en la década de 1870. Tanto en V2 como en LL se hallaron fragmentos de cerámica de tradición indígena o local, de cocción oxidante y reductora, respectivamente. Este tipo de cerámica utilitaria era común en los inventarios de las pulperías y casas de negocio, entre otros, como ollas y vajilla de cocina 
(Mayo 2000, 2007; Wibaux 2004). Brittez (2000:193) sugiere una producción local de las mismas y las adscribe a los sectores más humildes de la población no siendo reflejo directo de una categoría étnica.

El registro vítreo de los puestos LT3, MO y ESI se conforma casi exclusiva por recipientes de bebidas alcohólicas nacionales e importadas, fundamentalmente botellas de ginebra -de las marcas holandesas v. Hoytema \& C, Van den Berg, La China de Holanda, Schiedam- y cerveza. Mientras que en las estancias, además de este tipo de envases -p.e. ginebra holandesa Jürgen Peters en LL-, también se hallaron otros de contenidos como agua mineral, Bitter -p.e. Bitter des Basques de Bordeaux hallada en LL-, tónico -p.e. de la marca Genuine Sarsaparilla, Bristol's-New York en EIry comestibles -p-e- frascos de conserva en EIr-. En V2 botellas de vino y Hesperidina. Además, una botella de aguardiente de la marca J.T Gayen en ESI. Es de destacar la presencia de vasos en tres de los cuatro puestos, sobre todo en los más tempranos -LT3 y MO-, relacionado posiblemente con la gran frecuencia de recipientes de vidrio y gres de bebidas alcohólicas. Asimismo, las botellas de gres fueron habituales en los puestos rurales V2 -botellas de cerveza y tinta-, LT3 -botella de ginebra holandesa de la marca Bols- y en ESI. También en todas las estancias abordadas. Los estudios arqueológicos de botellas de gres de ámbitos rurales, como las estancias y los puestos bonaerense, son muy escasos, lo que dificulta la identificación de los envases, su origen y contenido, cronología e integración en las redes comerciales locales y regionales (Bagaloni y Martí, 2013). En cuanto al cuidado personal frascos de perfumería y farmacia de distintas características, colores y origen se descubrieron en LT3, V2 y en las cuatro estancias. Para LL encontramos objetos de uso personal como las pipas de caolín de origen francés (L. Fiolet St. Omer) y un tintero de gres inglés de gran porte usado para rellenar los tinteros de escritorio. Dejando en evidencia los hábitos de fumar y el nivel de alfabetización de Gomila y de los miembros de su familia a través de las cartas y memorias dejadas por éste. Es de destacar que estas pipas han sido muy usuales en todas las estancias aquí tratadas y en los puestos rurales tardíos como ESI y V2. De igual forma, en este último puesto se consignó un tintero de vidrio y un frasco de tina de gres.

\section{Figura 5}

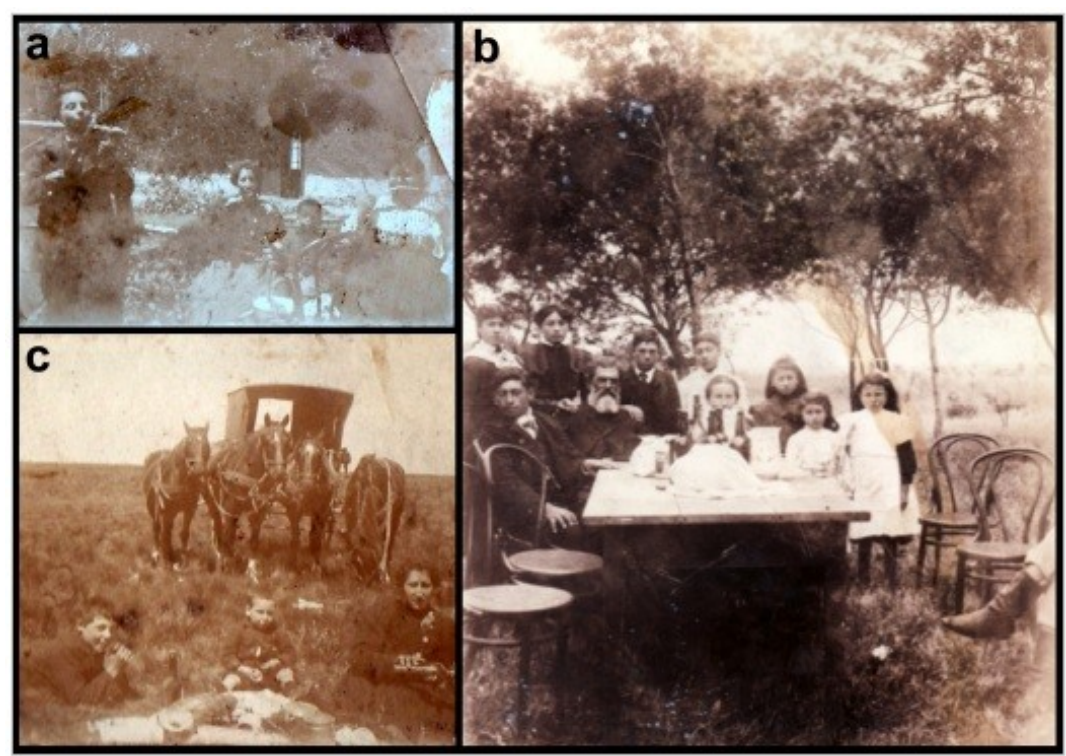


a. Los hijos de T. Gomila Juana, Máximo y Julio junto con Modesta Cardoso (amiga y vecina) comiendo un costillar al asador en LL

b. Un alto para almorzar camino a LL; Juana, Julio y Máximo Gomila. ‥ El mayordomo de LL y su familia momentos antes de comer (gentileza de V. Satas).

Por último, el registro fotográfico tomado por el propio Gomila retrata distintas maneras de apropiarse de la hora del almuerzo, tanto por parte de su familia como por la familia del mayordomo de su estancia. En Figura 5a se encuentran los hijos de Gomila junto con la hija de otro importante terrateniente vecino comiendo un costillar de vaca al asador debajo de un gran árbol en el patio de la estancia, un mediodía de verano. A pesar de estar tomando las costillas con las manos, vemos que por lo menos dos de ellos tienen su propio cuchillo. La presencia de chuchillos se registró también en LT3, LL y EIr. En esta última estancia es la única donde se encontraron otros utensilios metálicos como cuchara, mango de sartén y una chaira así como contenedores y latas de tabaco y/o yerba. Otra imagen registra una parada para almorzar en un viaje en coche a caballo desde Tres Arroyos a LL (Figura 5b), donde se observan botellas cilíndricas de vidrio junto con la comida sobre un mantel apoyado en el terreno, recipientes de metal, a Juana Gomila sirviendo alguna bebida en un vaso de metal y dos de sus hermanos sentados alrededor del mismo con alimentos en la mano. En la Figura 5 c, tomada en algún lugar cercano al casco de la estancia, se visualiza al mayordomo de la estancia LL junto con su familia, mujer e hijos, a punto de comer. En la misma fueron captadas, por lo menos, seis botellas de vidrio cilíndricas, una jarra y platos de loza. El resto de la comida se halla tapada con telas, suponemos para protegerla de los insectos y del frío ya que se nota por sus vestimentas que la foto fue sacada un día invernal. Todas estas fotografías fueron tomadas en distintos momentos del año 1899 a las 11 a.m., el horario establecido por la familia Gomila y el resto de sus empleados para el almuerzo.

\section{Consideraciones finales}

En líneas generales, podemos concluir que los contextos arqueológicos de puestos y estancias abordados tienen una serie de características comunes: 1) se ubican en áreas próximas a ríos, arroyos y lagunas, 2) muestran una clara preferencia en la producción, explotación y consumo de fauna doméstica, sobre todo de vacunos y ovinos, por sobre la fauna silvestre, 3) exhiben una gran cantidad y diversidad de productos de procedencia mayormente europeos manufacturados en vidrio, loza, gres, porcelana y caolín, de distintas características y funciones, en detrimento de los productos locales y regionales y, 4) la cronología estimada de todos estos conjuntos estudiados corresponde a la segunda mitad del siglo XIX, llegando en algunos casos a las primeras décadas del siglo XX. Esta investigación contribuyó al conocimiento sobre el emplazamiento de las distintas estructuras edilicias tratadas y las transformaciones en el tiempo, los materiales con que se construyeron destacándose la preferencia para la época de determinados artículos mayormente de origen francés, a discutir la distribución y circulación de la carne vacuna y ovina dentro de las estancias desde/hacia los puestos, a reconocer efectivamente los gustos por determinados artículos en la dieta rural y los hábitos domésticos de los habitantes bonaerenses, a identificar las diferencias sociales según el status de clase, entre otros aspectos.

El aporte de este trabajo es doble. Por un lado, se abordaron los primeros puestos rurales para el sur 
bonaerense y de temprana cronología -LT3 y MO- en comparación a los conocidos hasta el momento -V2 y ESI-. Por otro, constituye el primer artículo de síntesis y de análisis exclusivo de puestos y estancias rurales bonaerenses enmarcado dentro de la arqueología histórica. Esto implicó la integración de materiales arqueológicos junto con documentos escritos, fuentes gráficas y relatos orales. Asimismo, el diálogo continuo entre las investigaciones procedentes del campo de la arqueología y de la historia permitió ampliar y profundizar el conocimiento de un espacio (el sur bonaerense) y un período (la segunda mitad del siglo XIX) que comenzó a abordarse arqueológica y sistemáticamente en la última década. Este camino posibilitó que los restos arqueológicos materialicen, reflejen, amplíen y contrasten los datos aportados por la historia visualizando, a su vez, las microhistorias de los habitantes de los puestos rurales y estancias que perduraron en el tiempo. Futuras indagaciones arqueológicas permitirán ajustar las tendencias e ideas aquí desarrolladas.

\section{Agradecimientos}

Esta investigación se enmarcó en los proyectos dirigidos por la Dra. V. Pedrotta “Arqueología e historia de la frontera sur de Buenos Aires durante la segunda mitad del siglo XIX: campos, ejidos y tierras indígenas desde una mirada interdisciplinar” (PIP CONICET N³04/17) y “La construcción del territorio en la frontera sur de Buenos Aires en perspectiva arqueológica e histórica. Campos, ejidos y tierras indígenas en la segunda mitad del siglo XIX” (PICT AGENCIA N² 219/16). Todo lo expuesto en este artículo es de mi exclusiva responsabilidad.

\section{Referencias bibliográficas}

Bagaloni, V. N. (2010) Desde las orillas... Una comparación de los sitios La Libertad (Pdo. San Cayetano) y Las Toscas (Pdo. Tres Arroyos). En Mamül Mapu: pasado y presente desde la arqueología pampeana, M. Berón, L. Luna, M. Bonomo, C. Montalvo, C. Aranda y M. C. Aizpitarte (eds.), II: 215-230. Ayacucho: Libros del Espinillo.

Bagaloni, V. N. (2014a). Arqueología de los asentamientos fronterizos en el sudeste bonaerense (siglo XIX). Tesis doctoral inédita, 409 páginas. FACSO, UNICEN. Olavarría.

Bagaloni, V. N. (2014b). Arqueología en espacios fronterizos del sudeste bonaerense (siglo XIX): resultados de las primeras prospecciones. Intersecciones en Antropología 15: 05-22.

Bagaloni V. N. y L. Carrascosa Estenoz (2013). Estudio de huellas producidas con objetos de metal durante el último cuarto del siglo XIX en el sitio arqueológico La Libertad (partido de San Cayetano, Buenos Aires, Argentina). Revista del Museo de La Plata, Sección Antropología, 13 (87): 375-392.

Bagaloni, V. N. y V. Martí (2013). Ajustes metodológicos para el análisis macroscópico del gres cerámico. Estudio de conjuntos arqueológicos del sudeste bonaerense (siglo XIX). Arqueología 19 (2): 219-243.

Brittez, F. R. (2000). La comida y las cosas: una visión arqueológica de la campaña bonaerense de 
la segunda mitad del siglo XIX. En Vivir en la frontera. La casa, la dieta, la pulpería, la escuela (1770-1870), C. A. Mayo (ed.), 169-199. Buenos Aires: Editorial Biblos.

Brittez, F. R. (2002) Investigaciones en Arqueología Rural: Sitio Vizcacheras (Partido de Coronel Brandsen, Provincia de Buenos Aires). Campañas 1998-1999. En Arqueología Histórica Argentina. Actas del I Congreso Nacional de Arqueología Histórica, 395-403. Buenos Aires: Editorial Corregidor.

Brittez, F. R. (2004). Arqueología Rural en el partido de Coronel Brandsen, provincia de Buenos Aires. En: La Región Pampeana, su pasado arqueológico, C. Gradin y F. Oliva (eds.), 211-222. Buenos Aires: Editorial Laborde.

Brittez, F. R. (2006). Instrucciones para estancieros. Manuales de estancia y construcción del espacio pampeano en los albores del capitalismo industrial. En P. P. A. Funari y F. Brittez (comp.) Arqueología Histórica en América Latina. Temas y discusiones recientes, pp. 91-114. Mar del Plata: Ediciones Suárez.

Brittez, F. R. (2009). Zooarqueología, tafonomía y procesos de formación de sitios rurales pampeanos: estado de la cuestión y expectativas para momentos tardíos. Revista de Arqueología Histórica Argentina y Latinoamericana 3: 47-68.

Brittez, F. R. y M. Wibaux (2007) Una aproximación interdisciplinaria al mundo rural pampeano del siglo XIX. Arqueología Histórica del sitio “Casa de Negocio”, partido de General Alvarado, provincia de Buenos Aires. En VI Jornadas de Arqueología e Historia de las regiones pampeanas y patagónicas, Mar del Plata, CD.

Brittez, F. R. y M. Wibaux (2011). Investigaciones preliminares en el sitio "Estancia Ballenera Vieja”, un asentamiento de frontera del Sudeste Bonaerense. En Temas y problemas de la Arqueología Histórica, M. Ramos, A. Tapia, F. Bognanni, M. Fernández. V. Helfer, C. Landa, M. Lanza, E. Montanari, E. Néspolo, V. Pineau (eds.), I: 359-367. Luján: UNLu.

Cabrejas, L. L. (2000) Vida material en la frontera bonaerense (1736-1870). Vivienda, muebles e indumentaria. En Vivir en la frontera. La casa, la dieta, la pulpería, la escuela (1770-1870), editado por C. A. Mayo, pp. 41-70. Buenos Aires: Editorial Biblos.

Carrera, J. (2004). Pulperos rurales: entre la vida privada y la pública. Mundo Agrario 4 (8): 1-15.

Carrera, J. (2014). Vinos y aguardientes en las pampas rioplatenses 1770-1850. Revista Iberoamericana de Viticultura, Agroindustria y Ruralidad, 1(2): 21-37.

Correa, C. y M. Wibaux. (2000). Sabores de la pampa. Dietas y hábitos de consumo en la frontera bonaerense. En Vivir en la frontera. La casa, la dieta, la pulpería, la escuela (1770-1870), editado por C. A. Mayo, pp. 71-86. Buenos Aires: Editorial Biblos.

de Jong, I. y V. Satas (2011). Teófilo Gomila. Memorias de frontera y otros escritos. Buenos Aires: El Elefante Blanco.

Eiras, C. T. y M. E. P. Vassolo (1981). Historia del Partido de Tres Arroyos. Municipalidad de Tres Arroyos. Buenos Aires: Artes Gráficas Los Andes S.A. 
Garavaglia J. C. y J. Gelman (2003) Capitalismo agrario en la frontera. Buenos Aires y la región pampeana en el siglo XIX. Historia Agraria 29: 105-121.

García, M. S. (2014) Análisis de las prácticas y representaciones en torno a la circulación de bienes y personas en el Pago de la Magdalena durante la segunda mitad del siglo XVIII y siglo XIX Tesis doctoral inédita, 355 páginas. FCNyM, UNLP. La Plata.

García Lerena, M. S, y L. M. del Papa (2013). Una estancia ganadera pampeana del siglo XIX: Zooarqueología en el sitio El Santuario I, Magdalena, Buenos Aires (Argentina). Vestigios. Revista Latinoamericana de Arqueología Histórica 7 (2): 8-38.

Giovannetti, M. y V. Lema (2007). Circulación de bienes y patrones de descarte en la Estancia Iraola. Comechingonia Virtual 2: 84-105.

Gorraiz, R. (1935). Historia de Tres Arroyos. Indios, fronteras, combates, fundaciones y censos. Tres Arroyos: Editorial Tres Arroyos.

Hobsbawm, E.J. (1998). La era del capital. Buenos Aires: Crítica.

Infesta, M. E. (2003) La pampa criolla. Usufructo y apropiación privada de tierras públicas en Buenos Aires, 1820-1850. La Plata: Archivo Histórico de la Provincia de Buenos Aires.

Levene, R. (Dir.) (1941). Historia de la Provincia de Buenos Aires y formación de sus pueblos, T. II, La Plata: Archivo Histórico de la Provincia de Buenos Aires.

Levi, G. (1993). Sobre Microhistoria. En: Burke, Peter et al., Formas de hacer Historia: 119-143. Barcelona, Alianza Editorial.

Marschoff, M. (2007). Gato por liebre. Prácticas alimentarias en Floridablanca. Buenos Aires: Teseo.

Mayo, C. A. (editor) (2000). Vivir en la frontera: La casa, la dieta, la pulpería, la escuela (17701870). Buenos Aires: Editorial Biblos.

Mayo, C. A. (1996) La pulpería como empresa en Buenos Aires (1740-1830). Trabajos y Comunicaciones, (24): 95-132.

Mayo, C. A. (2007). Mostradores, clientes y fiados. Fuentes para el estudio de las pulperías de Buenos Aires y la pampa (siglo XIX). Mar del Plata: Ediciones Suárez.

Moreno, C. (1998). Patrimonio de la producción rural en el antiguo partido de Cañuelas. ICOMOS Comité Argentino; Arquitectura vernácula. Buenos Aires.

Mulazzi, J. A. (1938). K’la-Rome-Ko (Tres Arroyos). Tres Arroyos: Artes Gráficas F. Miralles.

Reguera, A. (2006). Patrón de estancias: Ramón Santamarina, una biografía de fortuna y poder en la Pampa. Buenos Aires: Eudeba.

Reguera, A. (1999). Estancias pampeanas del siglo XIX. Estrategia empresaria para su funcionamiento: chacras agrícolas y puestos ganaderos. Quinto Sol 3:53-82. 
Sábato, H. (1989). Capitalismo y ganadería en Buenos Aires. La fiebre del lanar 1850-1890. Buenos Aires: Sudamericana.

Sbarra, N. H. (1964). Historia del alambrado en la Argentina. Buenos Aires: Universitaria.

Sesto, C. (2005). La vanguardia ganadera bonaerense, 1856-1990. En Historia del capitalismo agrario pampeano. Tomo II. Buenos Aires: Siglo XXI.

Valencia., M. (2005) Tierras Públicas, tierras privadas. Buenos Aires 1852-1876. UNLP. La Plata.

Wibaux, M. I. (2004). Una mirada desde el mostrador. Dieta, hábitos alimenticios y comercio minorista en la campaña bonaerense, 1760-1870. Anuario CEH 4 (4): 125-142.

Zeberio, B. (1999). Un mundo rural en cambio. En Nueva Historia Argentina. Liberalismo, Estado y orden burgués (1852-1880). M. Bonaudo (dir), 4: 293-362. Buenos Aires: Sudamericana. 